\title{
Extraction, Purification, and Biological Activities of Flavonoids from Branches and Leaves of Taxus cuspidata S. et Z.
}

Ping Jiang,,${ }^{\mathrm{a}, *}$ Yajie Zhao, ${ }^{\mathrm{a}}$ Jia Xiong, ${ }^{\mathrm{b}}$ Fei Wang,,${ }^{\mathrm{a}, *}$ Lujie Xiao, ${ }^{\mathrm{a}}$ Siyao Bao, ${ }^{\mathrm{a}}$ and Xiangdong $\mathrm{Yu}^{\mathrm{a}}$

The optimal operational and process parameters were determined for the enzymatic hydrolysis and ultrasound-assisted extraction (EHUE) method of flavonoids extracted from Taxus cuspidata branches and leaves (TCBL), and the biological activity of obtained flavonoids was evaluated. According to single factor and central composite design experiments, the optimum key experimental parameters for EHUE were that pectinase enzyme concentration was $0.10 \mathrm{mg} \cdot \mathrm{mL}^{-1}$, enzymatic hydrolysis temperature was 48 ${ }^{\circ} \mathrm{C}$, and enzymolysis time was $39 \mathrm{~min}$. The yield of flavonoids from TCBL under the optimized conditions was $5.23 \% \pm 0.18 \%$. Four purified flavonoid compounds from TCBL extract were identified as 1) (E)-1-methoxy-2-O-(pcoumaroyl)-myo-inositol, 2) catechin, 3) epicatechin, and 4) quercetin-3-Oglucoside. Among the 4 compounds, compounds 2 and 3 showed higher antioxidant capacities, $\alpha$-amylase, and $\alpha$-glucosidase inhibitory activities. The statistical analysis showed that epicatechin and catechin were potent antioxidants and active agents for inhibiting type II diabetes. In addition, all 4 compounds exerted clear antitumor activity against MCF-7, Hela, and HepG2 cells. Especially, compound 4 had highest antitumor capacity against MCF-7 and Hela, while compound 1 was best at suppressing the proliferation of HepG2 cells.

Keywords: Taxus cuspidata, Extraction; Purification; Flavonoids; Biological activity

Contact information: a: College of Chemical Engineering, Nanjing Forestry University, Jiangsu Key Lab of Biomass-Based Green Fuels and Chemicals, Nanjing, Jiangsu 210037, China; b: Plants for Human Health Institute, Food Bioprocessing and Nutritional Sciences, North Carolina State University, North Carolina Research Campus, Kannapolis, NC 28081 USA;

*Corresponding authors: pingj_chem@njfu.edu.cn; hgwf@njfu.edu.cn

\section{INTRODUCTION}

The genus Taxus consists of 24 species and 55 varieties (Spjut 2007), which provides a source of biological and pharmacological active compounds such as taxanes. Paclitaxel is one of the most broadly used anticancer drugs, and there are many other taxane derivatives (Van Rozendaal et al. 2000; Hao et al. 2011). Taxus cuspidata Sieb et Zucc. (Japanese yew or spreading yew), which is native to Japan, Russia, Korea, and northeast China, has been used to treat inflammation, diabetes, renal disorders, and cancer as traditional medicine (Bajpai et al. 2014). More than 100 taxane compounds have been identified from this yew, including various skeletons (Kobayashi and Shigemori 1999, 2002; Shigemori and Kobayashi 2004), but there are still new taxane compounds being isolated (Li et al. 2013). Moreover, Taxus spp. contain numerous other compounds with pharmacological and biological activities other than taxane diterpenoids. A variety of fatty acids obtained from $T$. chinensis leaves have been identified using gas chromatography- 
mass spectrometry (GC-MS) (Tang et al. 2013). Yew alkaloid toxoids, which are commercially available, were quantified and discerned by liquid chromatography-mass spectrometry/ mass chromatography (LC-MS/MS) (Grobosch et al. 2013). Lignins and flavonoids have been isolated from Taxus (Tezuka et al. 2011). A new kind of heteropolysaccharide has been separated and purified from T. yunnanensis leaves using anion-exchange chromatography and GPC (Yan et al. 2013).

The extracts from Taxus have been reported to possess potent antidiabetic, antitumor, and immunity enhancing activities (Wu and Wu 2009; Zhang et al. 2012; Zheng et al. 2014). Phenolic compounds from $T$. cuspidata exert clear anticancer activity against Jurkat, MCF-7, T24, HT-29, and Hela cells (Elansary et al. 2019). Flavonoid extracts of $T$. yunnanensis could be underlying candidates for development of paclitaxel oral formulation, as they inhibit CYP3A4 and P-gp activity concurrently (Li et al. 2013). Aqueous extract from $T$. baccata has potent antitumor activities due to its inhibitory activity against adenosine deaminase (Durak et al. 2014). The alcohol extract of T. baccata has anti-inflammation activity, such as decreasing bronchial hyperreactivity and bronchodilating activity (Dutta et al. 2010; Patel et al. 2011).

The main purpose of this study was to develop an effective way to extract flavonoids from $T$. cuspidata. Ultrasound-assisted extraction intensifies cell disruption, improves mass transfer, and accelerates the solvent osmotic effect (Cai et al. 2014). In a previous study (Jiang et al. 2017a), the optimum process conditions of ultrasound-assisted extraction were an ethanol concentration of $60 \%$, extraction temperature of $60{ }^{\circ} \mathrm{C}$, extraction time of $60 \mathrm{~min}$, liquid to material of 19:1 (v/w), and ultrasonic power of $168 \mathrm{~W}$. In this study, enzymatic hydrolysis was added before ultrasound-assisted extraction, and an enzymatic hydrolysis and ultrasound-assisted extraction (EHUE) method was developed to increase the yield of flavonoids from T. cuspidata.

In this study, experimental design was used to determine the optimum values for the process variables, including enzymatic hydrolysis temperature, enzymolysis time, and enzyme concentration. Furthermore, the crude flavonoids were separated and purified with macroporous adsorption resin and Sephadex LH-20 column chromatography. The antioxidant activities of flavonoids from Taxus cuspidata branches and leaves (TCBL) were evaluated by radical scavenging of DPPH, and the in vitro inhibition of $\alpha$-amylase and $\alpha$-glucosidase activities were examined for antidiabetic properties. The anticancer properties of purified flavonoids were evaluated by inhibitory activities against MCF-7, Hela, and HepG2 cells in vitro.

\section{EXPERIMENTAL}

\section{Material}

Taxus cuspidata branches and leaves (moisture content: $6.33 \%$ ) were harvested in April 2017 in Rongcheng, China. TCBL materials were crushed and air-dried in the shade then finely ground to particles (approximately $425 \mu \mathrm{m}$ in diameter) using a multi-function pulverizer. Pectinase enzyme was purchased from Congdien Biological Co., Ltd in Shandong, China.

\section{Extractions}

The yield of flavonoids extracted by traditional solvent extraction method, ultrasound-assisted extraction method, and enzymatic hydrolysis and ultrasound-assisted 
extraction method were compared. Each extraction method was as follows:

1. Traditional solvent extraction: $3 \mathrm{~g}$ TCBL was weighed into a $100 \mathrm{~mL}$ conical flask, to which $42 \mathrm{~mL}$ of aqueous solution was added. The TCBL solution was treated with water bath at $50{ }^{\circ} \mathrm{C}$ for 40 min and filtrated. Then the filtrate was transfer to a $100 \mathrm{~mL}$ volumetric flask. The residue was extracted under the same conditions with $60 \%$ ethanol solution and then filtrated. The filtrates were combined, and the total volume was made constant to $100 \mathrm{~mL}$ with $60 \%$ ethanol.

2. Ultrasound-assisted extraction: $3 \mathrm{~g}$ TCBL was weighed into a $100 \mathrm{~mL}$ conical flask, to which $42 \mathrm{~mL}$ of $60 \%$ ethanol solution was added, with sonication for $40 \mathrm{~min}$ at an ultrasonic power of $144 \mathrm{~W}$. The solution was filtrated and transferred into a $100 \mathrm{~mL}$ volumetric flask. The residue was extracted in water bath with $60 \%$ ethanol solution under the same conditions and then filtrated. The filtrates were combined, and total volume was constant to $100 \mathrm{~mL}$ with extract solution.

3. Enzymatic hydrolysis and ultrasound-assisted extraction: $3 \mathrm{~g}$ TCBL was weighed into a $100 \mathrm{~mL}$ conical flask, to which $42 \mathrm{~mL} 0.1 \mathrm{mg} / \mathrm{mL}$ pectin enzyme solution was added (Jiang et al. 2019). The TCBL solution was treated with water bath at $50{ }^{\circ} \mathrm{C}$ for $40 \mathrm{~min}$ and filtrated. The filtrate was transferred into a $100 \mathrm{~mL}$ volumetric flask, and residue was extracted in water bath with $60 \%$ ethanol solution and sonicated for $40 \mathrm{~min}$ at an ultrasonic power of $144 \mathrm{~W}$ and then filtrated. The filtrates were combined, and total volume was made constant to $100 \mathrm{~mL}$.

\section{Single Factor Experiment}

Three grams of TCBL powder was dissolved in $42 \mathrm{~mL}$ pectinase enzyme solution with water bath and then extracted with ultrasound. The influence factors of different enzymolysis time, enzymatic hydrolysis temperature, and enzyme concentration were studied to develop the EHUE method.

\section{Response Surface Optimization}

Based on the result of single factor experiment, enzymolysis time, enzymatic hydrolysis temperature, and enzyme concentration were selected to design response surface experiments with 3 factors and 3 levels.

\section{Determination and Separation of Flavonoids}

The $60 \%$ ethanol extract of TCBL was diluted 10 times, and the absorbance of diluent was measured by the $\mathrm{NaNO}_{2}-\mathrm{Al}\left(\mathrm{NO}_{3}\right)_{3}$ colorimetric method (Han et al. 2015).

Desiccative and pulverized TCBL were extracted 3 times with $60 \%$ ethanol, and the extract solution was concentrated under reduced pressure to evaporate the ethanol. The extract was separated with different polarity solvents: petroleum ether, dichloromethane, ethyl acetate, n-butanol, and water for 5 times, respectively. The ethyl acetate extract was further isolated due to its highest antioxidant activity. Crude flavonoids from ethyl acetate extract were separated into several fractions by the macroporous adsorption resin method to remove pigments and other substances. Afterwards, components with higher flavonoid content were chromatographed over a Sephadex LH-20 column (Shanghai, China) eluted with water/methanol for purification.

Chromatographic analysis of flavonoids was performed on HPLC (Agilent 1200 Series, California, USA) using a C18 Column $(100 \mathrm{~mm} \times 4.6 \mathrm{~mm} \times 3.5 \mu \mathrm{m}$ Aglient Eclipse Plus C18) maintained at $25{ }^{\circ} \mathrm{C}$. The mobile phases were $0.1 \%$ deionized acetic acid (A) and methanol $(\mathrm{B})$ at a flow rate of $0.5 \mathrm{~mL} \cdot \mathrm{min}^{-1}$ with the following gradient programs: $10 \%$ 
to $30 \% \mathrm{~B}$ (0 to $15 \mathrm{~min}$ ), $30 \%$ to $60 \% \mathrm{~B}$ (15 to $25 \mathrm{~min}$ ), and $60 \%$ to $10 \% \mathrm{~B}$ (25 to $30 \mathrm{~min}$ ). The eluent was detected at a wavelength of $280 \mathrm{~nm}$. The injection volume was $5 \mu \mathrm{L}$ for every sample (Jiang et al. 2017b).

\section{Antioxidant Activity of Flavonoids from TCBL}

The antioxidant ability of sample solution was measured by calculating the 2,2diphenyl-1-picrylhydrazyl (DPPH) radical scavenging rate (Rosa et al. 2011), and the absorbance value was determined at $517 \mathrm{~nm}$. Vitamin C (Energy Chemical, Shanghai, China) was used as the control group.

\section{Antidiabetic Activity of Flavonoids from TCBL}

The antidiabetic activity of purified flavonoids was tested by $\alpha$-amylase and $\alpha$ glucosidase inhibitory activity (Jiang et al. 2017b). Acarbose (Bayer Healthcare Company Ltd, Beijing, China) was selected as the control group.

\section{Anticancer Activity of Flavonoids from TCBL}

The antitumor activity of purified flavonoids was examined in different cancer cell lines (MCF-7, Hela, and HepG-2) by using a 3-(4,5-dimethylthiazol-2-yl)-2,5diphenyltetrazolium bromide (MTT) method (Jiang et al. 2019). The antitumor drug etoposide (Beyotime Biotechnology, Nanjing, China) was selected as a control.

\section{Statistical Analyses}

Statistical analyses were conducted using Origin 8 software (OriginLab, Northampton, USA). Data were expressed as mean \pm SD. The response surface optimization experimental design was performed by Box-Behnken model of DesignExpert 8.0.6.1 software (Statease, Minneapolis, USA). All determinations were repeated 3 times. When $\mathrm{p}$-value $<0.05$ was considered significant different.

\section{RESULTS AND DISCUSSION}

\section{Comparison of Different Enzymatic Hydrolysis and Ultrasound-Assisted Extraction (EHUE) Methods}

Table 1 shows that the highest total flavonoids yield (5.16\%) was using pectinase aqueous solution after water bath and then ultrasonic extraction with $60 \%$ ethanol solution.

Table 1. Comparative Results of Different Enzymatic Hydrolysis and Ultrasoundassisted Extraction (EHUE) Methods

\begin{tabular}{|c|l|c|}
\hline Trial Number & \multicolumn{1}{|c|}{ Methods } & $\begin{array}{c}\text { Total Flavonoids Yield } \\
\text { (w/w dry material \%) }\end{array}$ \\
\hline 1 & $\begin{array}{l}\text { Aqueous solution water bath } \\
\text { treatment + 60\% ethanol solution } \\
\text { water bath extraction }\end{array}$ & $4.08 \pm 0.07$ \\
\hline 2 & $\begin{array}{l}60 \% \text { ethanol solution ultrasonic } \\
\text { treatment }\end{array}$ & $4.86 \pm 0.02$ \\
\hline 3 & $\begin{array}{l}\text { Enzyme aqueous solution water } \\
\text { bath treatment }+60 \% \text { ethanol } \\
\text { solution ultrasonic extraction }\end{array}$ & $5.16 \pm 0.05$ \\
\hline
\end{tabular}


The yield was $26.47 \%$ higher than that of the traditional solvent extraction method (water bath treatment $+60 \%$ ethanol solution water bath extraction) and $6.17 \%$ higher than that of ultrasound-assisted extraction $(60 \%$ ethanol solution ultrasonic treatment $+60 \%$ ethanol solution ultrasonic extraction). Due to the high content of pectin and viscose resin in the TCBL, it was very difficult to filter the solution by enzyme treatment and ultrasound at the same time, and the yield was decreased by 3.61\% (data not shown). Therefore, ultrasonic extraction of pectinase from TCBL by water bath and then $60 \%$ ethanol solution with ultrasound-assisted coupling was the best method for the extraction of flavonoids, pectinase. The extraction process of this method was studied.

\section{Results of Single Factor Experiments of Flavonoids Extraction Process} Effects of enzyme concentration on total flavonoids yield

Enzymatic hydrolysis was first carried out at $50{ }^{\circ} \mathrm{C}$ and $40 \mathrm{~min}$ at different enzyme concentrations $\left(0,0.05,0.1,0.15,0.2\right.$, and $\left.0.25 \mathrm{mg} \cdot \mathrm{mL}^{-1}\right)$. The second extraction was sonicated with $60 \%$ ethanol at $144 \mathrm{~W}$ for $40 \mathrm{~min}$. The effects of different enzyme concentration on total flavonoids yield extracted from TCBL by EHUE are shown in Fig. 1(A). When the enzyme concentration was between 0.05 and $0.15 \mathrm{mg} \cdot \mathrm{mL}^{-1}$, the yield of total flavonoids increased gradually as the enzyme concentration increased. When the enzyme concentration reached $0.15 \mathrm{mg} \cdot \mathrm{mL}^{-1}$, the total flavonoids yield was the maximum of $5.20 \%$; after the concentration exceeded $0.15 \mathrm{mg} \cdot \mathrm{mL}^{-1}$, the yield began to diminish. The possible reason is that with the increasing of pectinase dosage, pectinase decomposes pectin into small molecular substances in the TCBL, making cell wall loose, reducing the diffusion resistance, making flavonoids fully dissolved, and thus increasing the yield of total flavonoids. However, as the concentration of pectinase continued to increase, large doses of pectinase hydrolyzed pectin in the cell wall of TCBL. The hydrolysate produced by pectinase had strong adsorption on flavonoids, but the yield of total flavonoids decreased (Wang and Liu 2004). Therefore, the concentration of pectinase at $0.15 \mathrm{mg} \cdot \mathrm{mL}^{-}$ ${ }^{1}(2.24 \mathrm{mg} / \mathrm{g}$ of the dry weight of the raw material) was initially determined as the optimal enzymatic concentration of the coupling of enzymatic and ultrasound-assisted extraction method for the total TCBL flavonoids.

\section{Effects of Enzymatic Hydrolysis Temperature on Total Flavonoids Yield}

The pectinase concentration of $0.15 \mathrm{mg} \cdot \mathrm{mL}^{-1}(2.24 \mathrm{mg} / \mathrm{g}$ of absolute dry weight of raw materials) was selected, and the enzymatic hydrolysis time was $40 \mathrm{~min}$, under different enzymatic hydrolysis temperatures. The second extraction was then sonicated with $60 \%$ ethanol at $144 \mathrm{~W}$ for $40 \mathrm{~min}$. The effects of enzymatic hydrolysis temperatures at 30, 40, 50,60 and $70{ }^{\circ} \mathrm{C}$, respectively, on total flavonoids yield from TCBL were investigated. The results are shown in Fig. 1(B).

From Fig. 1(B), as enzymatic hydrolysis temperature increased in the range of 30 to $50{ }^{\circ} \mathrm{C}$, the yield of total flavonoids gradually increased. The yield reached the maximum of $5.17 \%$ when the enzymatic hydrolysis temperature was $50{ }^{\circ} \mathrm{C}$. When the temperature went beyond $50{ }^{\circ} \mathrm{C}$, the total flavonoids yield started to decrease gradually. This might be due to the fact that the optimum temperature of pectinase was 40 to $50{ }^{\circ} \mathrm{C}$ in general and the activity of pectinase was the best in this temperature range. When the temperature of enzymatic hydrolysis was from $30^{\circ} \mathrm{C}$ to $50^{\circ} \mathrm{C}$, the activity of pectinase gradually increased with temperature rising. 


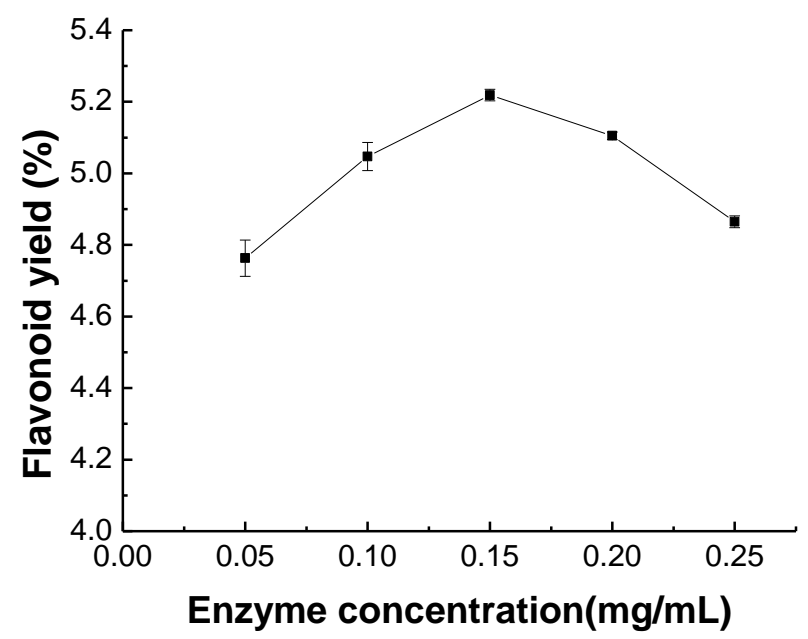

A

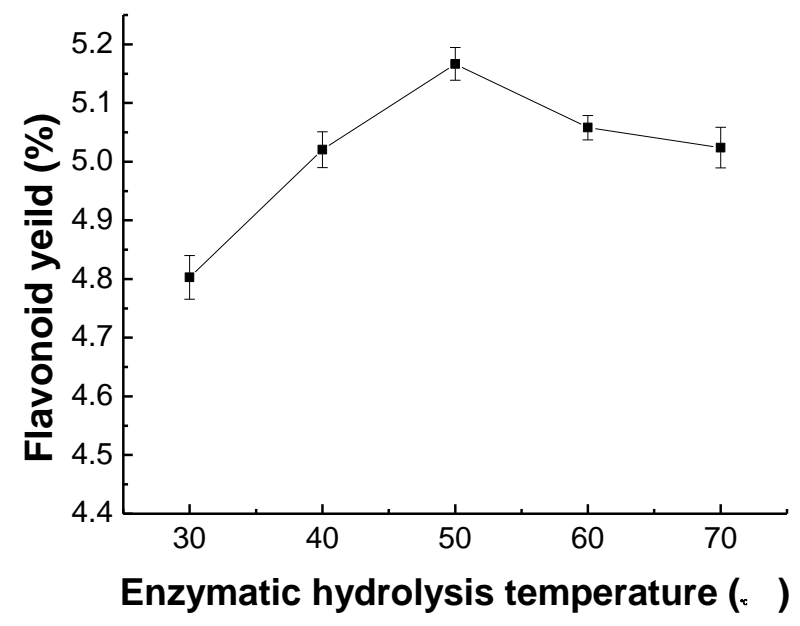

B

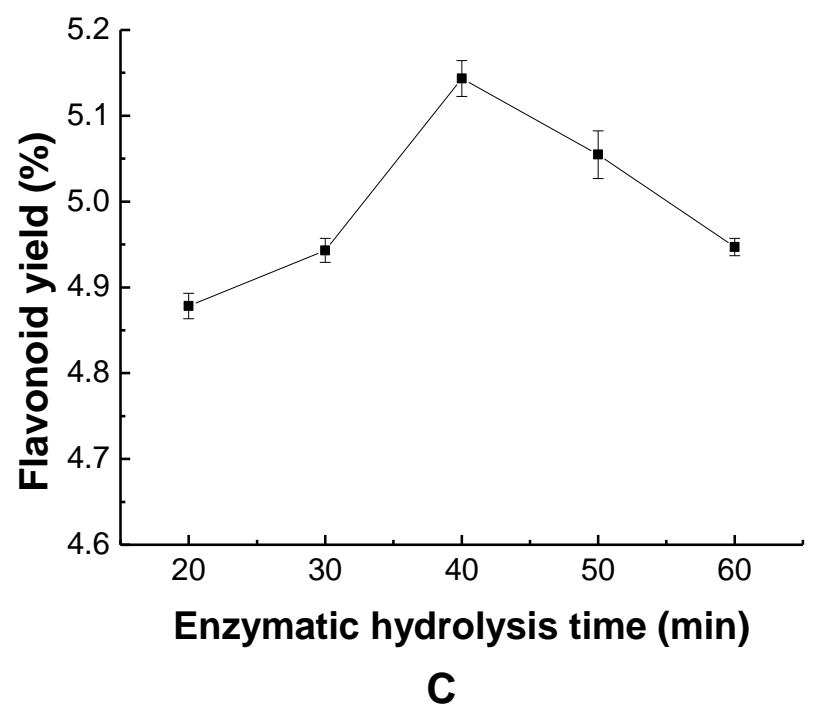

Fig. 1. Effect of different conditions on total flavonoids yield 
The extraction rate gradually increased as a result; but when the temperature of enzymatic hydrolysis was over $50{ }^{\circ} \mathrm{C}$, with the increase in temperature, the yield of total flavonoids in TCBL began to decrease, which might be due to the heat denaturation of enzyme proteins and the decrease of pectinase activity caused by high temperature, thus resulting in the decrease of the extraction rate of total flavonoids in TCBL. Therefore, 50 ${ }^{\circ} \mathrm{C}$ was judged to be the optimal temperature to extract total flavonoids from TCBL by EHUE.

\section{Effects of Enzymolysis Time on Total Flavonoids Yield}

The pectinase concentration of $0.15 \mathrm{mg} \cdot \mathrm{mL}^{-1}(2.24 \mathrm{mg} / \mathrm{g}$ of absolute dry weight of raw materials) was selected. The enzymatic hydrolysis was carried out at $50{ }^{\circ} \mathrm{C}$ under different enzymatic hydrolysis times. The second extraction was then sonicated with $60 \%$ ethanol at $144 \mathrm{~W}$ for $40 \mathrm{~min}$. Finally, the two portions of extract were combined. The effects of different enzymatic hydrolysis time $(20,30,40,50$, and $60 \mathrm{~min})$ on yield of total flavonoids from TCBL by EHUE method were explored. The results are shown in Fig. 1(C). As the enzymatic hydrolysis time reached $40 \mathrm{~min}$, the total flavonoids yield reached to the maximum value $5.14 \%$. Within $20 \mathrm{~min}$ to $40 \mathrm{~min}$, the yield of total flavonoids gradually increased with enzymatic hydrolysis time increasing, which might due to the full utilization of the catalytic ability of the enzyme. When time was more than $40 \mathrm{~min}$, the yield of total flavonoids began to decrease, which may due to the long enzymatic hydrolysis time leading to the inactivation of part of pectinase, thus reducing the yield of total flavonoids. Therefore, $40 \mathrm{~min}$ was adopted as the optimal enzymatic hydrolysis time.

Table 2. Results of Response Surface Analysis

\begin{tabular}{|c|c|c|c|c|}
\hline Run. & $\begin{array}{c}\mathrm{X}_{1} \text { (Enzyme } \\
\text { concentration, } \\
\left.\mathrm{mg} \cdot \mathrm{mL}^{-1}\right)\end{array}$ & $\begin{array}{c}\mathrm{X}_{2} \text { (Enzymatic } \\
\text { hydrolysis } \\
\left.\text { temperature, }{ }^{\circ} \mathrm{C}\right)\end{array}$ & $\begin{array}{c}\mathrm{X}_{3} \\
\text { (Enzymolysis } \\
\text { time, min) }\end{array}$ & $\begin{array}{c}\text { Total } \\
\text { flavonoids } \\
\text { yield(\%) }\end{array}$ \\
\hline 1 & 0.15 & 60 & 50 & 4.93 \\
\hline 2 & 0.20 & 50 & 30 & 4.74 \\
\hline 3 & 0.10 & 60 & 40 & 5.04 \\
\hline 4 & 0.15 & 40 & 50 & 4.81 \\
\hline 5 & 0.10 & 50 & 50 & 4.98 \\
\hline 6 & 0.15 & 50 & 40 & 5.06 \\
\hline 7 & 0.15 & 40 & 30 & 4.88 \\
\hline 8 & 0.20 & 40 & 40 & 4.72 \\
\hline 9 & 0.20 & 50 & 50 & 4.78 \\
\hline 10 & 0.20 & 60 & 40 & 4.92 \\
\hline 11 & 0.15 & 50 & 40 & 5.05 \\
\hline 12 & 0.15 & 60 & 30 & 4.92 \\
\hline 13 & 0.15 & 50 & 40 & 5.08 \\
\hline 14 & 0.10 & 50 & 30 & 5.03 \\
\hline 15 & 0.15 & 50 & 40 & 5.05 \\
\hline 16 & 0.15 & 50 & 40 & 5.07 \\
\hline 17 & 0.10 & 40 & 40 & 5.08 \\
\hline
\end{tabular}

\section{Analysis of Optimal Extraction Process by Response Surface Methodology}

Experimental design was carried out according to Box-Behnken model (Hou et al. 2013), based on results of single-factor experiment and results were displayed in Table 2. 
The quadratic polynomial regression equation is shown in Eq. 1.

$$
\begin{aligned}
& Y=5.06-0.12 X_{1}+0.04 X_{2}-8.75 * 10^{-3} X_{3}+0.060 X_{1} X_{2}+0.022 X_{1} X_{3}+0.020 X_{2} X_{3}-0.062 X_{1}^{2}- \\
& 0.060 X_{2}^{2}-0.12 X_{3}^{2}
\end{aligned}
$$

To test the accuracy of the regression equation, further statistical analysis was conducted on the test results in Table 2, and the total flavonoids yield response surface variance analysis results were obtained as shown in Table 3.

Table 3. Variance Analysis for Extraction Yield of Total Flavonoids

\begin{tabular}{|c|c|c|c|c|c|c|}
\hline $\begin{array}{c}\text { Variation } \\
\text { Source }\end{array}$ & $\begin{array}{c}\text { Sum of } \\
\text { Squares }\end{array}$ & $\begin{array}{c}\text { Degree of } \\
\text { Freedom }\end{array}$ & $\begin{array}{c}\text { Mean } \\
\text { Square }\end{array}$ & $F$-Value & p-Value & Significant \\
\hline model & 0.25 & 9 & 0.027 & 191.38 & $<0.0001$ & ${ }^{* *}$ \\
\hline$X_{1}$ & 0.12 & 1 & 0.12 & 819.19 & $<0.0001$ & ${ }^{* *}$ \\
\hline$X_{2}$ & 0.013 & 1 & 0.013 & 89.15 & $<0.0001$ & ${ }^{* *}$ \\
\hline$X_{3}$ & $6.125 \times 10^{-4}$ & 1 & $6.125 \times 10^{-4}$ & 4.27 & 0.0777 & \\
\hline$X_{1} X_{2}$ & 0.014 & 1 & 0.014 & 100.30 & $<0.0001$ & ${ }^{* *}$ \\
\hline$X_{1} X_{3}$ & $2.025 \times 10^{-3}$ & 1 & $2.025 \times 10^{-3}$ & 14.10 & 0.0071 & ${ }^{* *}$ \\
\hline$X_{2} X_{3}$ & $1.6 \times 10^{-3}$ & 1 & $1.6 \times 10^{-3}$ & 11.14 & 0.0124 & ${ }^{*}$ \\
\hline$X_{1}{ }^{2}$ & 0.016 & 1 & 0.016 & 113.64 & $<0.0001$ & ${ }^{* *}$ \\
\hline$X_{2}{ }^{2}$ & 0.015 & 1 & 0.015 & 104.70 & $<0.0001$ & ${ }^{* *}$ \\
\hline$X_{3}{ }^{*}$ & 0.058 & 1 & 0.058 & 403.18 & $<0.0001$ & ${ }^{* *}$ \\
\hline residual & $1.005 \times 10^{-3}$ & 7 & $1.436 \times 10^{-4}$ & & & \\
\hline lack of fit & $3.250 \times 10^{-4}$ & 3 & $1.083 \times 10^{-4}$ & 0.64 & 0.6295 & \\
\hline pure error & $6.800 \times 10^{-4}$ & 4 & $1.700 \times 10^{-4}$ & & & \\
\hline $\begin{array}{c}\text { correlation } \\
\text { total }\end{array}$ & 0.25 & 16 & & & & \\
\hline
\end{tabular}

$\mathrm{X}_{1}$ : enzyme concentration, $\mathrm{X}_{2}$ : enzymatic hydrolysis temperature, $\mathrm{X}_{3}$ : enzymolysis time

* Significant difference $(0.01<p<0.05)$; ${ }^{* *}$ Significant difference $(p<0.01)$.

As shown in Table 3, the lack of fit p-value $(0.6295>0.05)$ was non-significant, and $\mathrm{p}<0.0001$ indicated that the regression equation was significant. The determination coefficient $\mathrm{R}^{2}>0.9$ demonstrated that the model was well-fitted (Zou et al. 2012). Thus, the regression equation was reliable to determine the optimal flavonoids extracting process.

In the regression model, the p-value of enzyme concentration $\left(X_{1}\right)$ and enzymatic hydrolysis temperature $\left(X_{2}\right)$ was less than 0.0001 , which indicated the effect on the extraction rate of total flavonoids from TCBL was significant. The main factors influencing total flavonoids yield extracted from TCBL by enzymatic hydrolysis and ultrasoundassisted extraction were: enzyme mass concentration $\left(X_{1}\right)>$ enzymatic hydrolysis temperature $\left(X_{2}\right)>$ enzymolysis time $\left(X_{3}\right)$. The interaction terms $X_{1} X_{2}$ and $X_{1} X_{3}$ had an extremely significant effect, while the interaction term $X_{2} X_{3}$ had a significant effect. The quadratic terms $X_{1}{ }^{2}, X_{2}{ }^{2}$, and $X_{3}{ }^{2}$ had an extremely significant effect, indicating that the factors had a significant interaction effect rather than a simple linear relationship on the total flavonoids yield $(\mathrm{p}<0.0001)$. The results of response surface methodology are shown in Fig. 2. 


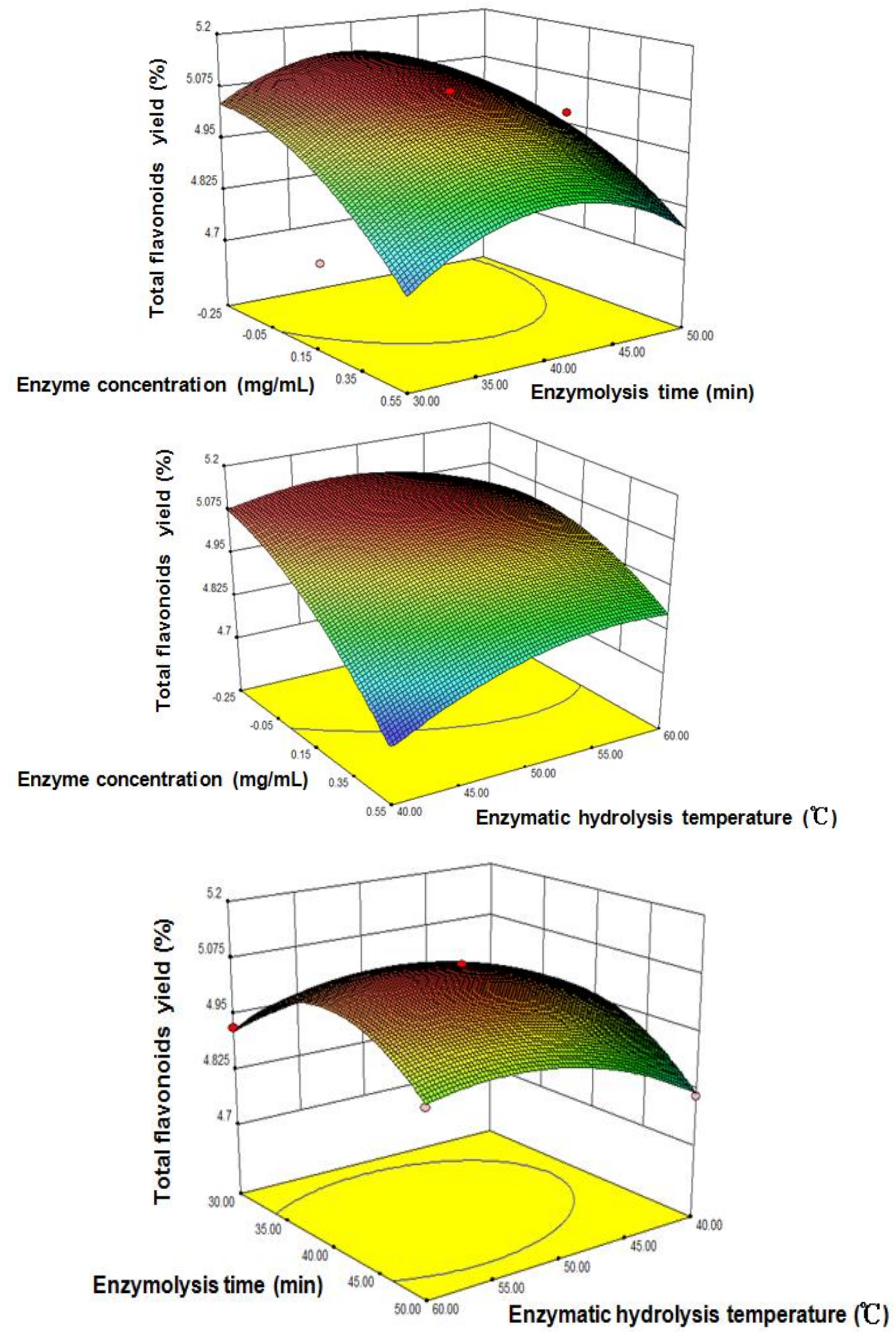

Fig. 2. Results of response surface experiments

In the response surface diagram, the steeper the surface was, the greater the effect this factor had on total flavonoids yield (Jiang et al. 2017a). As shown in Fig. 2, the surface of enzyme mass concentration and enzymatic hydrolysis temperature was steep, indicating 
that these two factors had a significant influence on the yield of total flavonoids, while the surface of enzymatic hydrolysis time was relatively smooth, indicating that the influence was weak. Through analysis of response surface software, optimal extracting conditions were obtained: enzyme mass concentration of $0.1 \mathrm{mg} \cdot \mathrm{mL}^{-1}$ (enzyme accounted for 1.49 $\mathrm{mg} \mathrm{g}^{-1}$ of the absolute dry weight of the raw material), enzymatic hydrolysis temperature of $48{ }^{\circ} \mathrm{C}$, enzymatic hydrolysis time of $39 \mathrm{~min}$. Under these conditions, the predicted value of total flavonoids in TCBL was 5.13\%. In order to test whether the experimental results were consistent with the real situation, 6 confirmatory tests were conducted on the optimal extraction technology conditions, and the actual yield of total flavonoids extracted from TCBL was 5.28\%, 5.34\%, 5.19\%, 5.24\%, 5.10\%, and 5.25\%, respectively. The average actual value was $5.23 \%$, which had a relatively small error compared with the predicted data. Moreover, the measurement results were stable and had good repeatability, indicating that the process conditions obtained by the response surface optimization were reliable. Therefore, the optimal technological conditions for enzymatic hydrolysis and ultrasoundassisted extraction were $0.1 \mathrm{mg} \cdot \mathrm{mL}^{-1}$ mass concentration enzyme solution (the absolute dry weight of the enzyme in the raw material was $1.49 \mathrm{mg} \mathrm{g}^{-1}$ ), the enzymatic hydrolysis temperature was $48{ }^{\circ} \mathrm{C}$, and the enzymatic hydrolysis time was $39 \mathrm{~min}$.

\section{Purified flavonoids from TCBL}

The $5 \mathrm{~g}$ ethyl acetate extract was measured, and after gradient elution by AB-8 macroporous adsorption resin, 16 separated components Fr1-Fr16 were obtained with a total recovery rate of $85.07 \%$.

Through HPLC analysis, the chemical components of Fr5 and Fr7 were relatively small, and there were substances with large peak areas, which are relatively pure. Therefore, Fr5 and Fr7 were selected for further separation and purification.

Compound 1 and compound 2 were obtained from Fr7 by water elution and $40 \%$ methanol elution of LH-20 glucan gel chromatographic column, while compound 3 was obtained from Fr5 by $60 \%$ methanol elution of LH-20 glucan gel chromatographic column. At the same time, a relatively pure compound 4 was also isolated from Fr5. Then HPLCMS, UV, IR, and NMR were performed regarding the structural characterization of chemicals.

\section{Structural Characterization of Compound 1}

Compound 1 is yellow powder with a melting point of 120 to $122{ }^{\circ} \mathrm{C}$. The UV absorption spectrum in Fig. 3 shows that the compound had a maximum absorption wavelength at 235 and $311 \mathrm{~nm}$, and the liquid phase shows a single peak at the retention time $t_{\mathrm{R}}=13.033 \mathrm{~min}$ (Fig. S1). The purity of compound 1 was calculated to be more than $95 \%$ by area normalization. According to mass spectrogram 8 , the mass charge ratio of the excimer ion peak $[\mathrm{M}-\mathrm{H}]^{-}$of the compound was 339, so the molecular weight of the compound was 340 . As shown in the infrared spectrum, $1629 \mathrm{~cm}^{-1}$ may be the absorption peak of the compound $\mathrm{C}=\mathrm{C}$, the wide peak of $3403 \mathrm{~cm}^{-1}$ may be the stretching vibration peak of $-\mathrm{OH}, 1701 \mathrm{~cm}^{-1}$ may be the stretching vibration peak of the ester carbonyl group, $2927 \mathrm{~cm}^{-1}$ may be the antisymmetric stretching vibration peak of $\mathrm{CH}$ in $-\mathrm{O}-\mathrm{CH}_{3}$, and 1604 $\mathrm{cm}^{-1}, 1517 \mathrm{~cm}^{-1}$, and $1439 \mathrm{~cm}^{-1}$ may be the absorption peaks of $\mathrm{C}=\mathrm{C}$ on the benzene ring. The molecular formula of this compound is $\mathrm{C}_{16} \mathrm{H}_{20} \mathrm{O}_{8}$, which is a new compound, named (E) -1-methoxy-2-o-(p-coumaroyl)-myo-inositol (Wu et al. 2010). Its structure is shown in Fig. 6. 


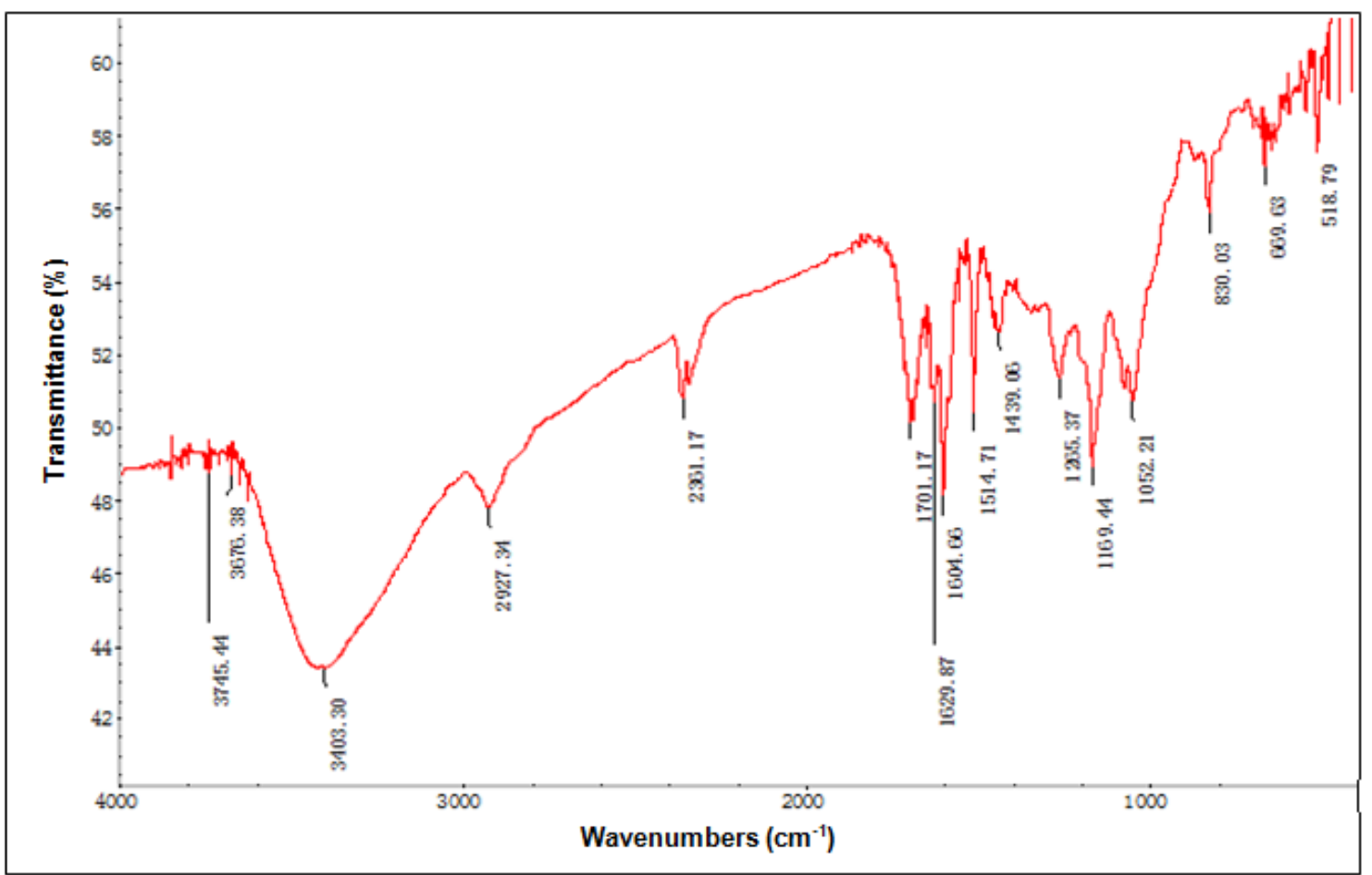

Fig. 3. FTIR spectrum of compound 1

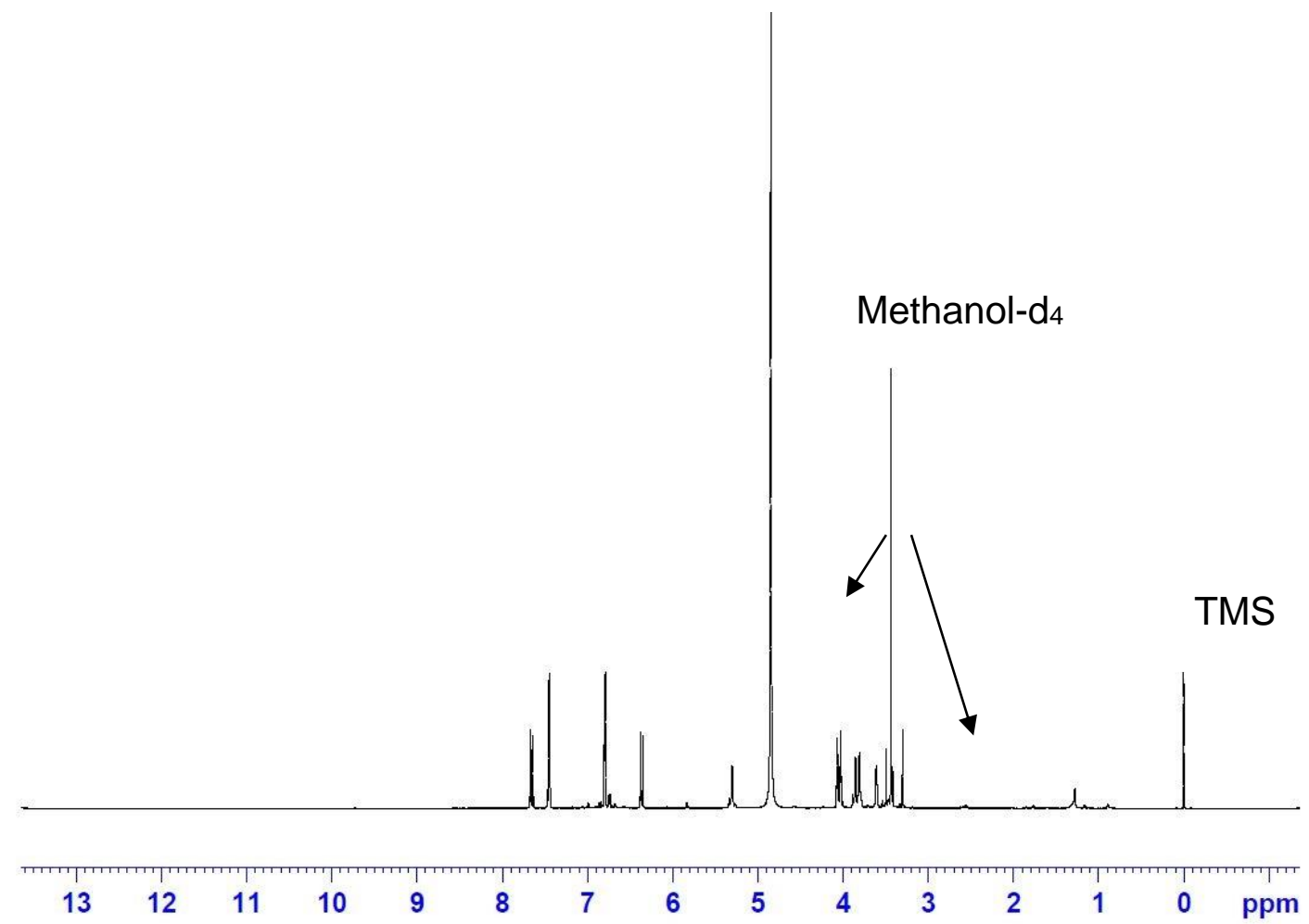

Fig. 4. ${ }^{1} \mathrm{H}$ NMR spectrum of compound1 


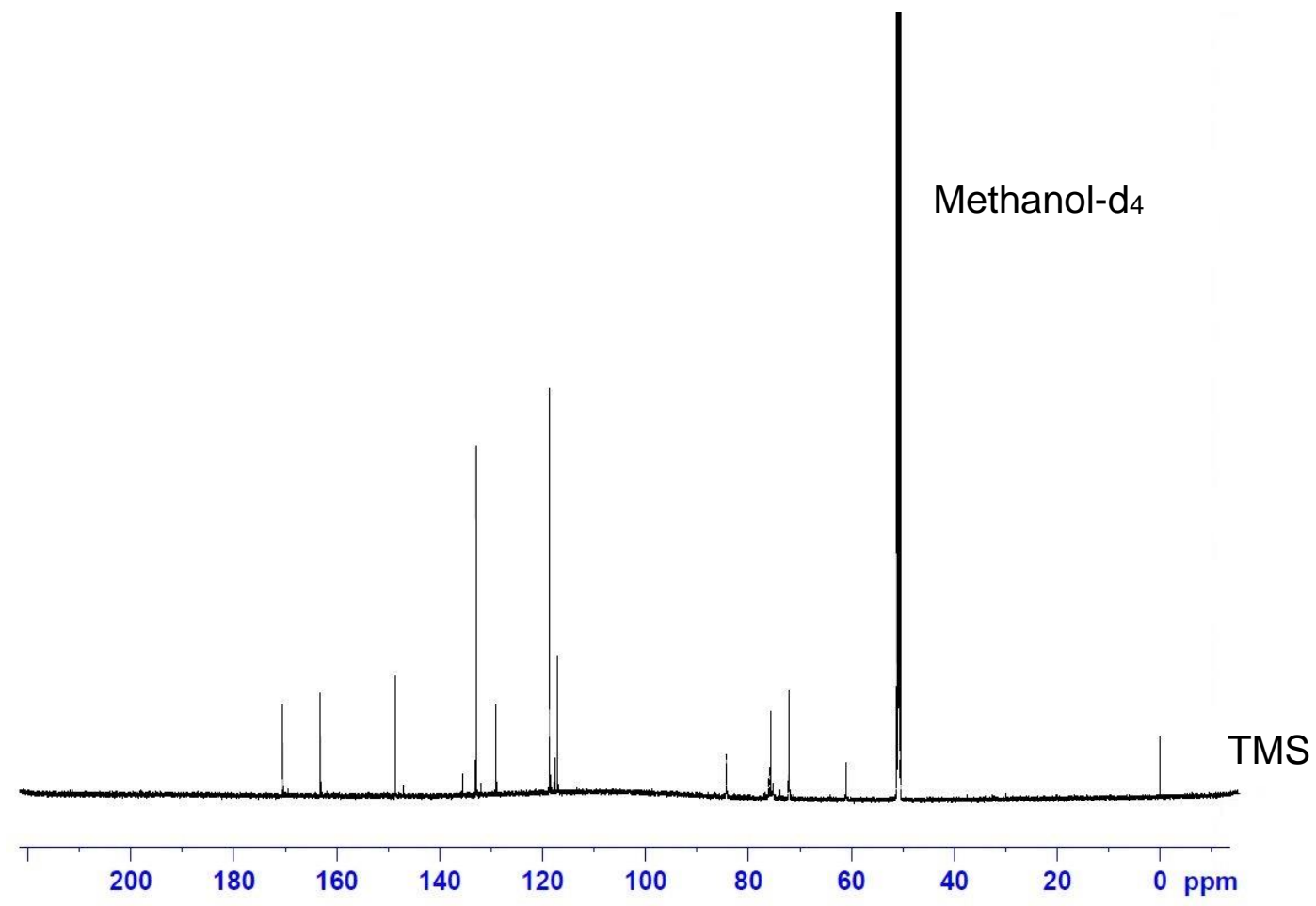

Fig. 5. ${ }^{13} \mathrm{C}$ NMR spectrogram of compound1

1H-NMR spectrum information: 1H NMR (700 MHz, methanol-d4):Delta TMS [3.53 H-1, dd, J=3.2, 6.5 Hz), 5.33 (H-2, dd, J=3.2, $6.7 \mathrm{~Hz}), 4.00$ (H-3, dd, J=6.7, $11.6 \mathrm{~Hz}), 3.85$ (H-4, dd, J=6.6, 11.6 Hz), 3.70 (H-5, dd, J=6.6, $13.3 \mathrm{~Hz}$ ), 4.07 (H-6, DDD, J=3.2, 8.1, 13.3 Hz].7.45 [H-2', d, J=9.8 Hz), $6.88(\mathrm{H}-3$ ', d, J=9.8 Hz), $6.88(\mathrm{H}-5$ ', d, J=9.8 Hz], the delta 7.45 [H-6 ', d, J=9.8 Hz), 7.62 (H-7', d, J=18.1 Hz), 6.66 (H-8', d, J=18.1 Hz), 3.49 (1$\left.\mathrm{OCH}_{3}, \mathrm{~s}\right)$

13C-NMR spectrum information: 13C NMR (175 MHz, methane-d 4$)$ : $\delta_{\mathrm{TMS}} 84.2(\mathrm{C}-$ 1), 75.2 (C-2), 72.1 (C-3), 75.6 (C-4), 75.2 (C-5), 72.0 (C-6), 128.9 (C-1'), 132.9 (C-2'), 118.4 (C-3'), 163.1 (C-4'), 118.4 (C-5'), 132.9 (C-6'), 146.9 (C-7'), 117.8 (C-8'), 170.4 $\left(\mathrm{C}^{-9}\right), 61.0\left(1-\mathrm{OCH}_{3}\right)$. The data above basically agreed with the literature (Wu et al. 2010).

Fig. 6. Structure of compound 1

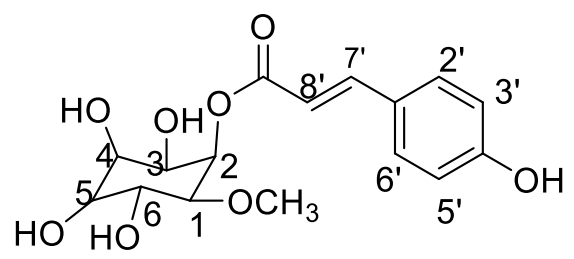

\section{Structural Characterization of Compound 2}

Compound 2 is dark brown powder with a melting point of 236 to $237^{\circ} \mathrm{C}$. Figure S4 shows that there is a maximum absorption peak at 234 and $278 \mathrm{~nm}$, and Fig. S5 shows that the liquid phase diagram has a single peak at the retention time $t_{\mathrm{R}}=14.367 \mathrm{~min}$. According to the mass spectrogram in Fig. S6, the mass charge ratio of the excimer ion peak $[\mathrm{M}-\mathrm{H}]^{-}$of the compound was $m / z=289$, so the molecular weight of the compound was 290. 


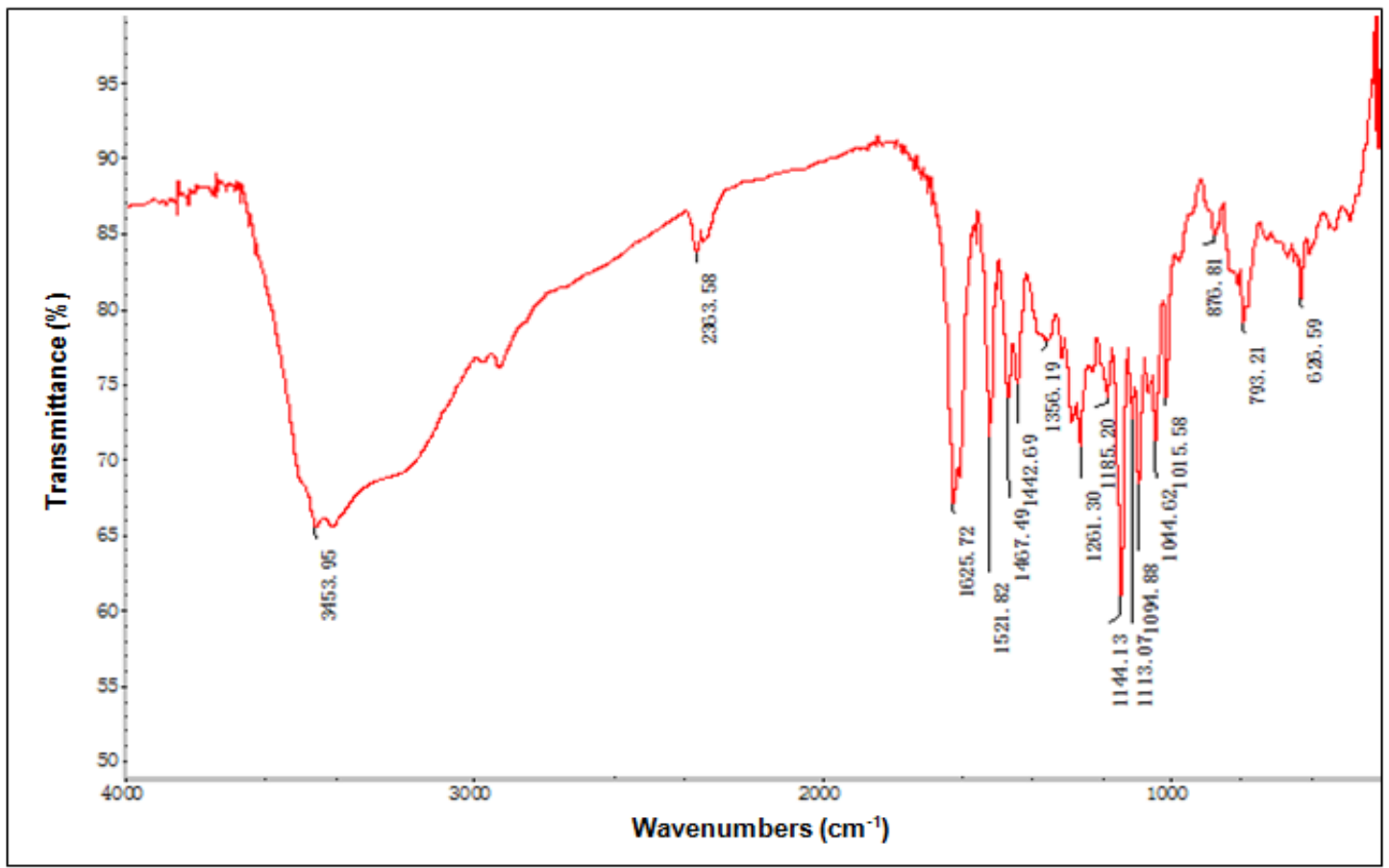

Fig. 7. FTIR spectrum of compound 2

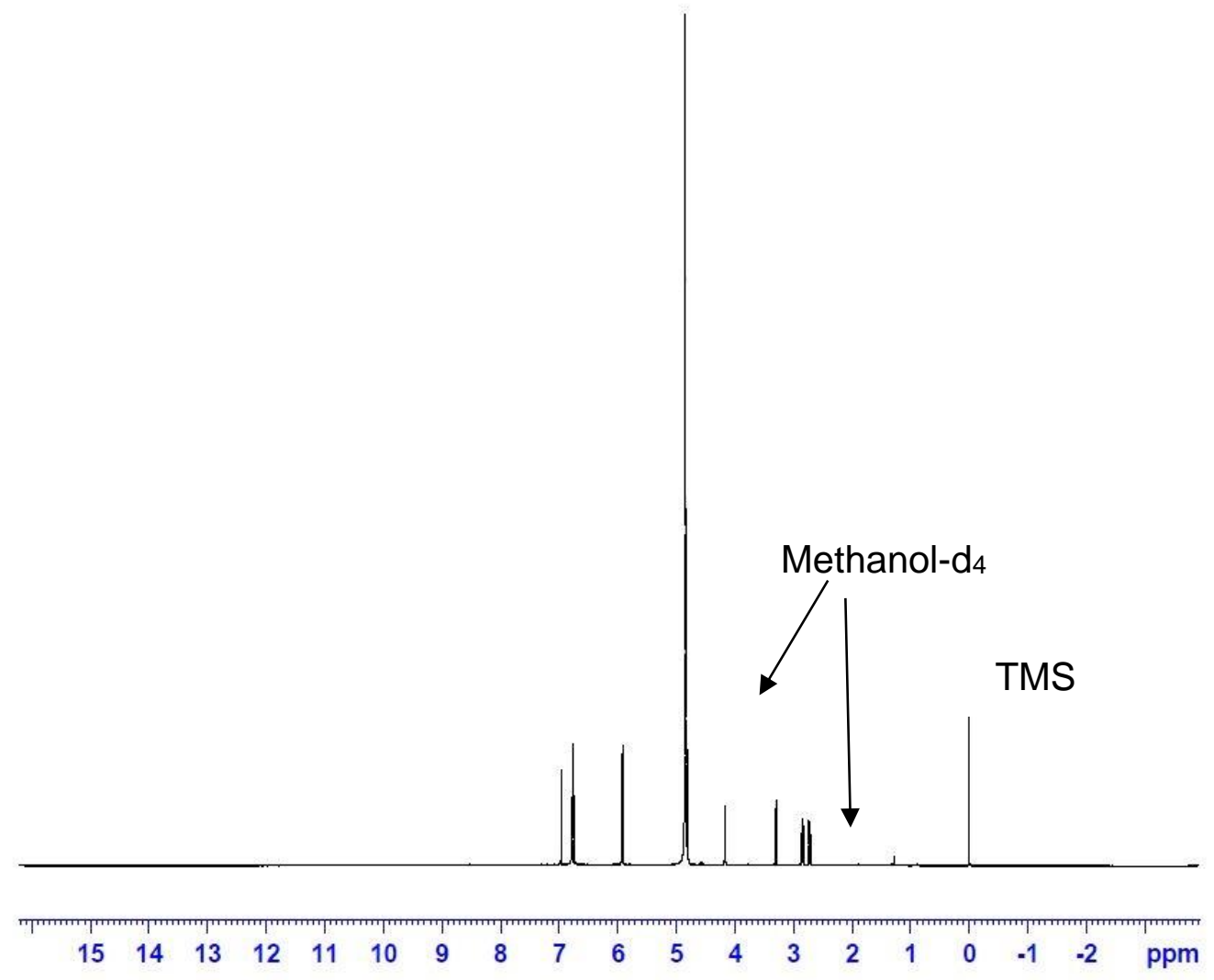

Fig. 8. ${ }^{1} \mathrm{H}$ spectrum of compound 2 


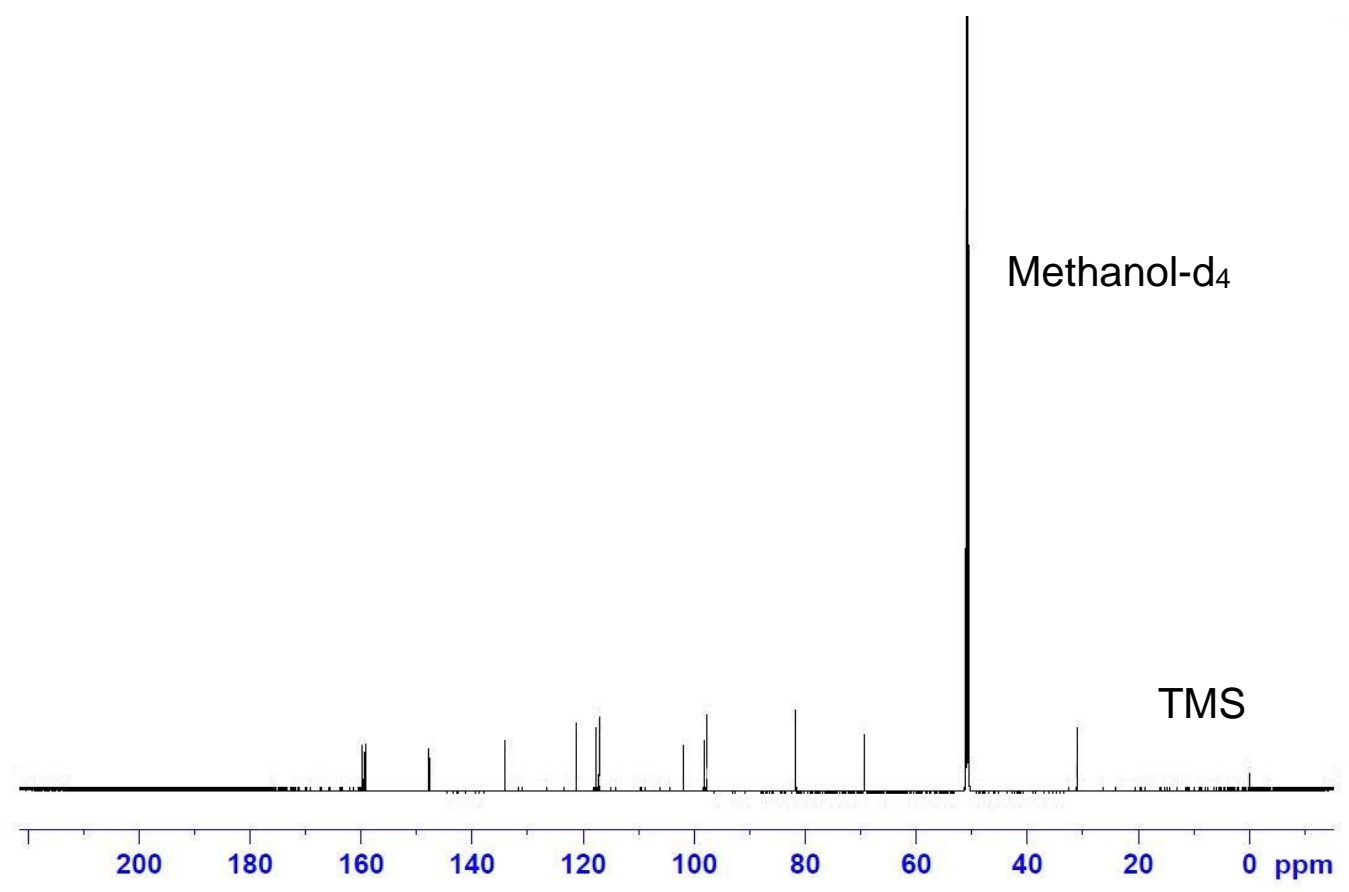

Fig. 9. ${ }^{13} \mathrm{C}$ NMR spectrogram of compound 2

According to the infrared spectrum in Fig. 7, the wide peak of $3453 \mathrm{~cm}^{-1}$ may be the stretching vibration peak of $-\mathrm{OH}, 1356 \mathrm{~cm}^{-1}$ may be the in-plane deformation vibration of phenolic hydroxyl, $1144 \mathrm{~cm}^{-1}$ may be the stretching vibration of $\mathrm{C}-\mathrm{O}$ bond of phenolic hydroxyl, and $1625 \mathrm{~cm}^{-1}, 1521 \mathrm{~cm}^{-1}, 1469 \mathrm{~cm}^{-1}$, and $1442 \mathrm{~cm}^{-1}$ may be the absorption peaks of carbon-carbon double bond on the benzene ring. The molecular formula of this compound is $\mathrm{C}_{15} \mathrm{H}_{14} \mathrm{O}_{6}$, which is epicatechin. The structure is shown in Fig.10.

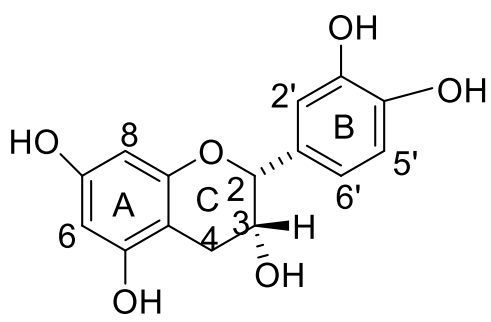

Fig. 10. Structure of compound 2

1H-NMR spectrum information: $1 \mathrm{H}$ NMR (700 MHz, methanol-d4): $\delta$ TMS $4.55[\mathrm{H}-$ 2, m], 4.21 [H-3,ddd,J=3.2,4.6,1.6Hz],2.48[H-4a,ddd,J=4.6,16.1, 0.8Hz], 2.82 [H-4b, ddd, $\mathrm{J}=3.2,16.1,0.9 \mathrm{~Hz}], 5.85$ [H-6, d, J=2.2Hz], 5.92 [H-8, d, J=2.2Hz], 7.03 [H-2', d, J=1.8Hz], $6.75\left[\mathrm{H}-5^{\prime}, \mathrm{d}, \mathrm{J}=8.1 \mathrm{~Hz}\right], 6.70\left[\mathrm{H}-6^{\prime}, \mathrm{ddd}, \mathrm{J}=1.8,8.1,0.7 \mathrm{~Hz}\right]$

13C-NMR spectrum information: 13C NMR (175 MHz, methanol-d 4$)$ : $\delta_{\mathrm{TMS}} 81.6$ (C-2), 69.2 (C-3), 31.0 (C-4), 101.8 (C-4a), 159.4 (C-5), 97.6 (C-6), 159.8 (C-7), 98.1 (C8), 159.1 (C-8a), 134.0 (C-1'), 117.0 (C-2'), 147.7 (C-3'), 147.5 (C-4'), 117.6 (C-5'), 121.1 (C-6'). The data above basically agreed with the literature (Cren-Olivé et al. 2002; Davis et al. 2015). 


\section{Structural Characterization of Compound 3}

Compound 3 was a white powder with a melting point of 160 to $162{ }^{\circ} \mathrm{C}$. According to Fig. S7, compound 3 had the maximum absorption peaks at 235 and $278 \mathrm{~nm}$. As shown in the liquid phase (Fig. S8), there was a single peak at the retention time $t_{\mathrm{R}}=6.567 \mathrm{~min}$, and the purity of compound 3 was calculated to be more than $95 \%$ by area normalization. According to mass spectrometry in Fig. S9, the compound presented $m / z 289[\mathrm{M}-\mathrm{H}]^{-}$as precursor ion in negative ionization mode, showing molecular weight 290 of the compound.

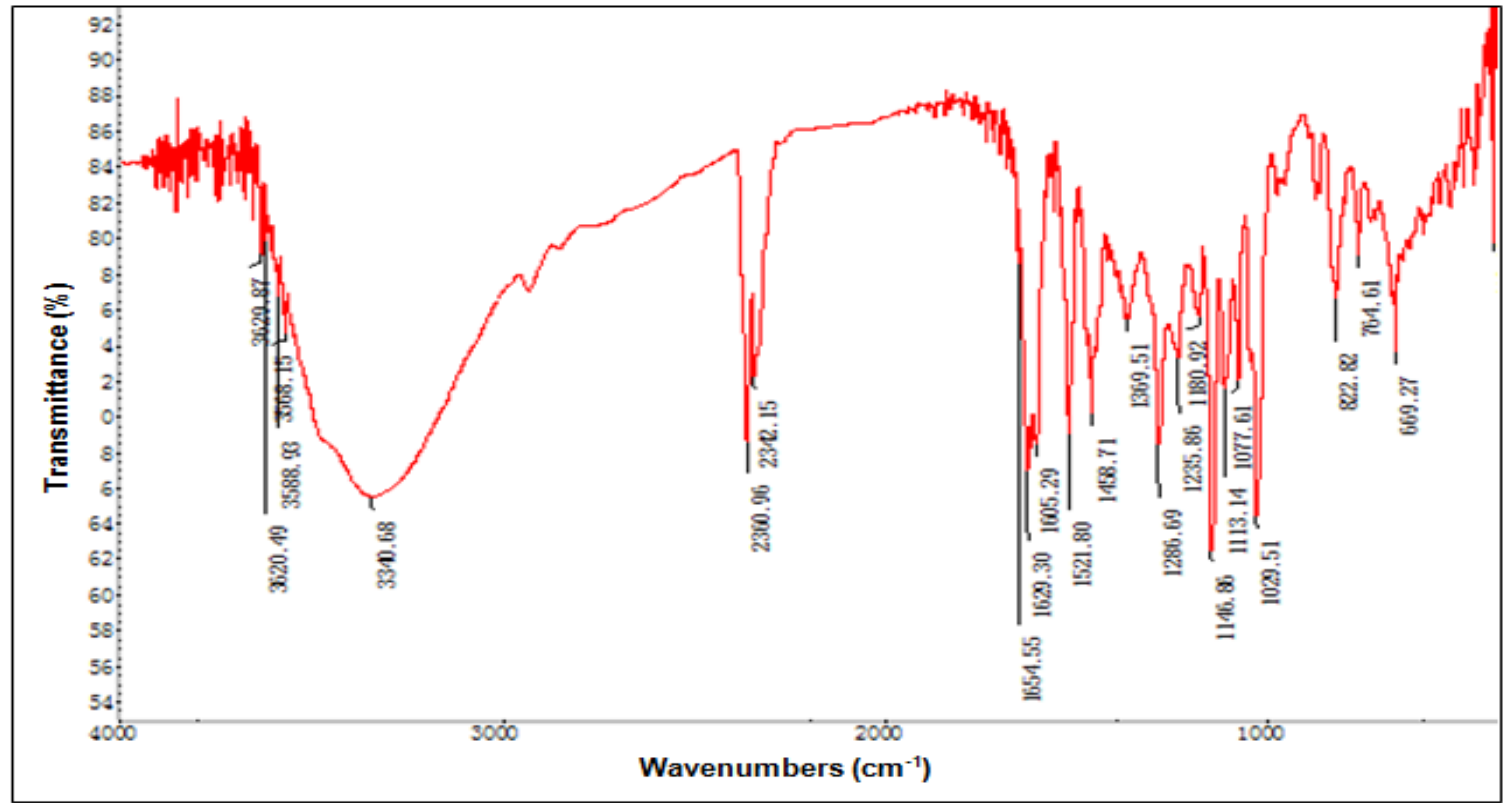

Fig. 11. FTIR spectrum of compound 3

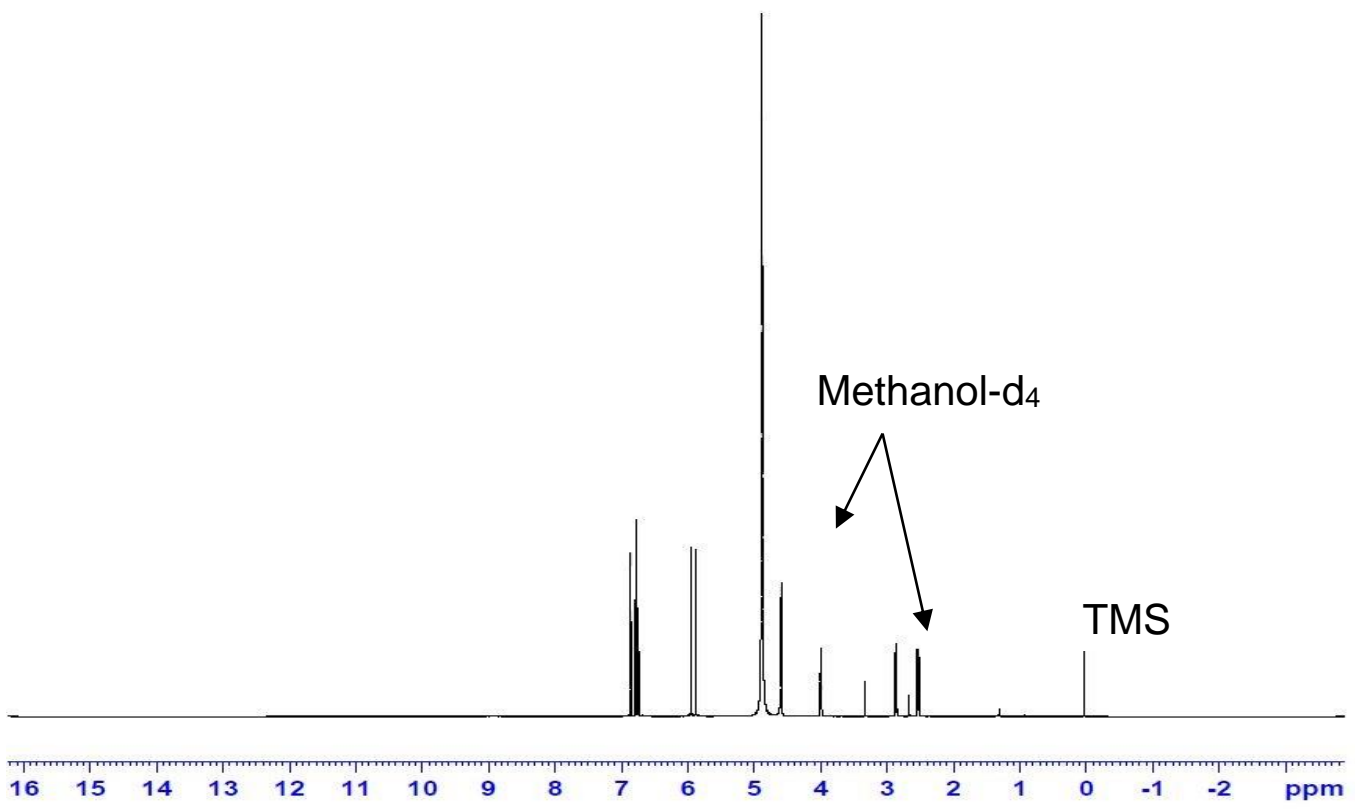

Fig. 12. ${ }^{1} \mathrm{H}$ spectrum of compound 3 
As shown in the infrared spectrum in Fig. 11, the wide peak of $3340 \mathrm{~cm}^{-1}$ may be the stretching vibration peak of $-\mathrm{OH}, 1369 \mathrm{~cm}^{-1}$ may be the in-plane deformation vibration of phenolic hydroxyl, $1146 \mathrm{~cm}^{-1}$ may be the stretching vibration of $\mathrm{C}-\mathrm{O}$ bond of phenolic hydroxyl, and $1629 \mathrm{~cm}^{-1}, 1605 \mathrm{~cm}^{-1}, 1521 \mathrm{~cm}^{-1}$, and $1458 \mathrm{~cm}^{-1}$ may be the characteristic absorption peaks of $\mathrm{C}=\mathrm{C}$ on the benzene ring. The molecular formula of this compound is $\mathrm{C}_{15} \mathrm{H}_{14} \mathrm{O}_{6}$, which is catechin, and its structure is shown in Fig.14. Compound 3 was also analyzed by TLC thin plate chromatography in Fig. S10. Chloroform: methanol 8:2 was used as the developing agent to draw fluorescent spots under ultraviolet light. Iodine/silica gel color developer was used for color development.

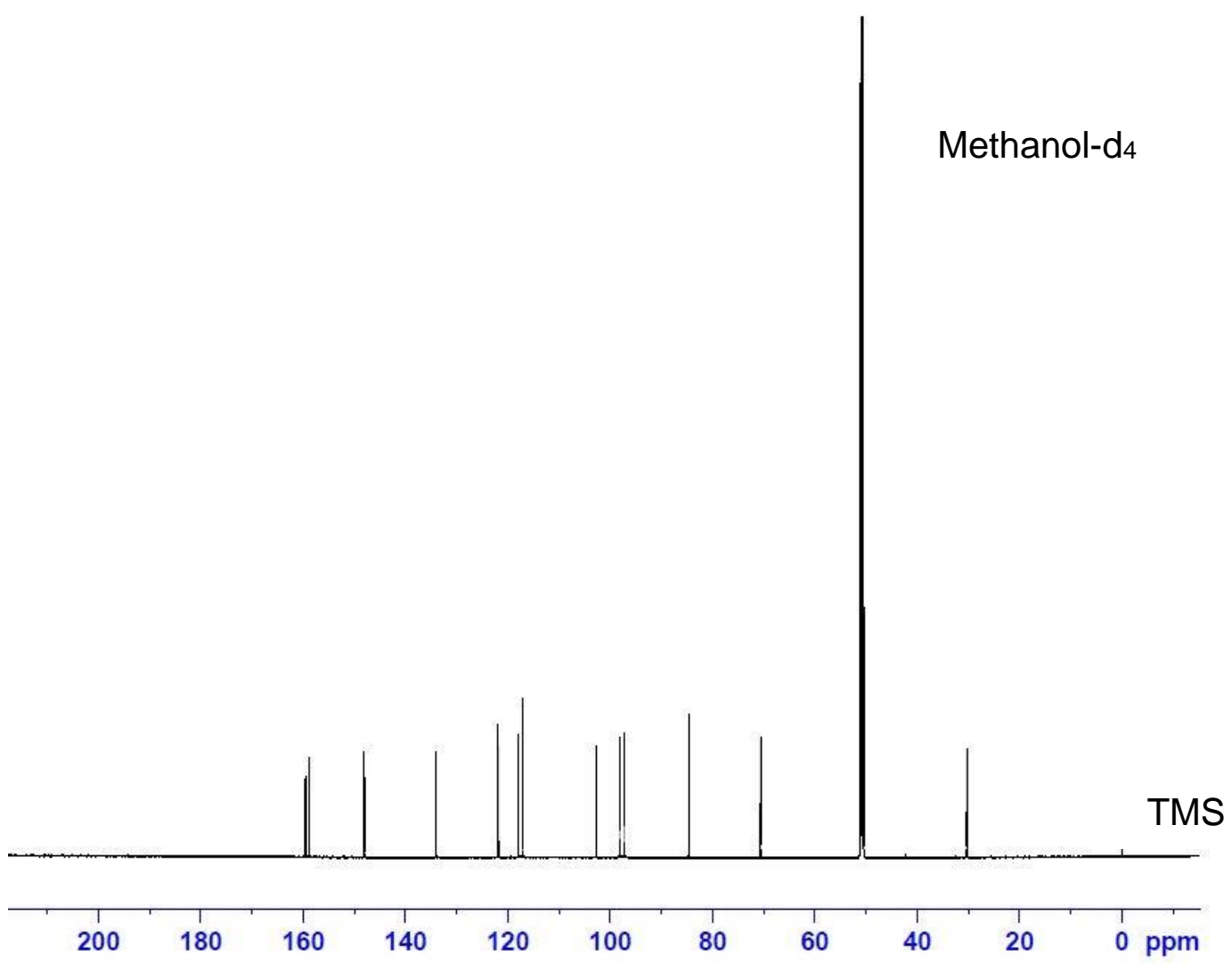

Fig. 13. ${ }^{13} \mathrm{C}$ NMR spectrogram of compound 3

1H-NMR spectrum information: $1 \mathrm{H}$ NMR (700 MHz, methanol-d4): $\delta$ TMS 4.55 [H-2, d, J=7.8 Hz], 3.96 [H-3, ddd, J=5.6,8.1,7.8Hz], 2.48 [H-4a, dd, J=8.1,16.1Hz], 2.82 [H-4b, dd, J=5.6, 16.1Hz], 5.85 [H-6, d, J=2.2 Hz], 5.92 [H-8, d, J=2.2 Hz], 6.83 [H-2',d, $\mathrm{J}=1.8 \mathrm{~Hz}], 6.75\left[\mathrm{H}-5^{\prime}, \mathrm{d}, \mathrm{J}=8.1 \mathrm{~Hz}\right], 6.70\left[\mathrm{H}-6^{\prime}, \mathrm{dd}, \mathrm{J}=1.8,8.1 \mathrm{~Hz}\right]$

13C-NMR spectrum information: 13C NMR (175 MHz, methanol-d 4$)$ : $\delta$ TMS 84.6 (C-2), 70.6 (C-3), 30.3 (C-4), 102.6 (C-4a), 159.3 (C-5), 97.2 (C-6), 159.6 (C-7), 98.0 (C8), 158.7 (C-8a), 134.0 (C-1'), 117.0 (C-2'), 148.0 (C-3'), 148.0 (C-4'), 117.8 (C-5'), 121.8 (C-6'). The data above basically agreed with the data in literature (Hye et al. 2009; Davis et al. 2015). 


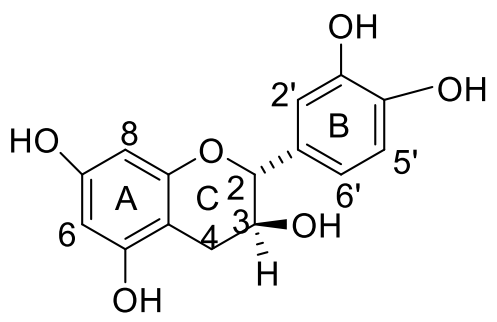

Fig. 14. Structure of compound 3

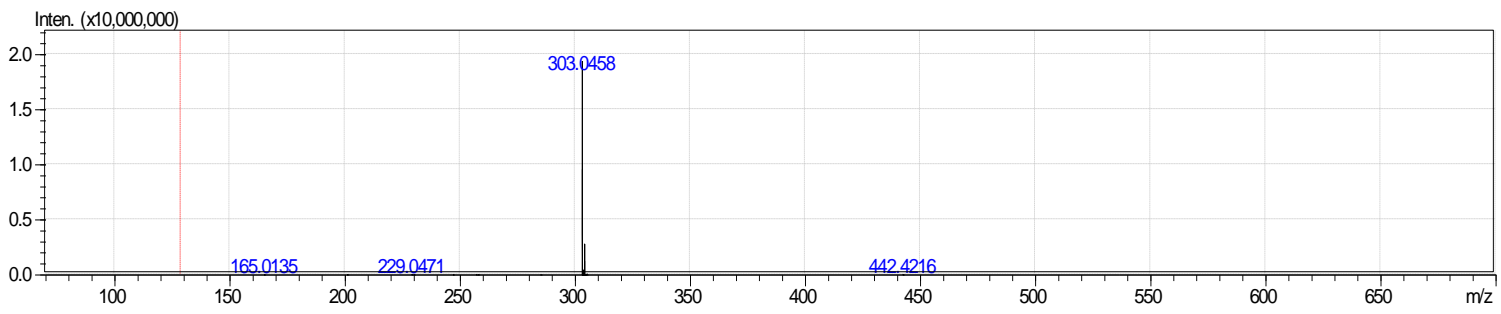

Fig. 15. Ms/Ms spectrum of compound 4

Compound 4 was isolated from Fr5 with the largest wavelength ultraviolet absorption at 255 and $368 \mathrm{~nm}$. The quasi molecular ion peaks of $[\mathrm{M}+1]^{+} \mathrm{m} / \mathrm{z} 465$ indicates that the molecular weight was 464 . The $\mathrm{MS}^{2}$ spectrometry showed a fragmentation ion at $[\mathrm{M}+1]^{+} \mathrm{m} / \mathrm{z}, 303$, so the fragment was tentatively identified as quercetin. Compared with the compound precursor ion $[\mathrm{M}+1]^{+} \mathrm{m} / \mathrm{z} 465$, the molecular weight decreased by 162 which probably meant that one molecule of the glucose group had fallen off. The liquid retention time of the compound was $t_{\mathrm{R}}=32.1 \mathrm{~min}$, which was compared with that of the reference substance quercetin-3-O-glucoside. Their retention time was the same. Therefore, the molecular formula of the compound was identified as $\mathrm{C}_{21} \mathrm{H}_{20} \mathrm{O}_{12}$, and the compound 4 was identified as quercetin-3-O-glucoside. Because the purity of this compound was relatively low and the yield was not considerable, it was not been studied for antioxidant and antidiabetic activity.

Fig. 16. Structure of compound 4<smiles>O=c1c(O[C@@H]2O[C@H](CO)[C@@H](O)[C@H](O)[C@H]2O)c(-c2ccc(O)c(O)c2)oc2cc(O)cc(O)c12</smiles>

\section{Antioxidant Activity}

Three purified flavonoids were assayed at a range of concentrations (10 to 60 $\left.\mu \mathrm{g} \cdot \mathrm{mL}^{-1}\right)$. Vitamin $\mathrm{C}(\mathrm{Vc})$ was used as a positive control. As shown in Fig. 17, the DPPH• radical clearance rate of compounds 2 and 3 increased with the mass concentration rising. By comparing the $\mathrm{IC}_{50}$ value, $V_{\mathrm{C}}\left(14.48 \mu \mathrm{g} \cdot \mathrm{mL}^{-1}\right)>\operatorname{compound} 2\left(16.88 \mu \mathrm{g} \cdot \mathrm{mL}^{-1}\right)>$ compound $3\left(20.20 \mu \mathrm{g} \cdot \mathrm{mL}^{-1}\right)$ were listed in the order from large to small. This result 
indicated that compounds 2 and 3 had significant antioxidant activity, among which the IC50 of compound 2 was only slightly less than that of $V_{\mathrm{C}}$, indicating that compound 2 had very strong antioxidant activity. With the increase of the concentration of compound 1 , $\mathrm{DPPH} \bullet$ radical scavenging rate remained almost unchanged and low, indicating that compound 1 had almost no antioxidant activity. This may be because compounds 2 (epicatechin) and 3 (catechin) have polyhydroxyl structures in the benzene ring, and they are effective at scavenging free radicals.

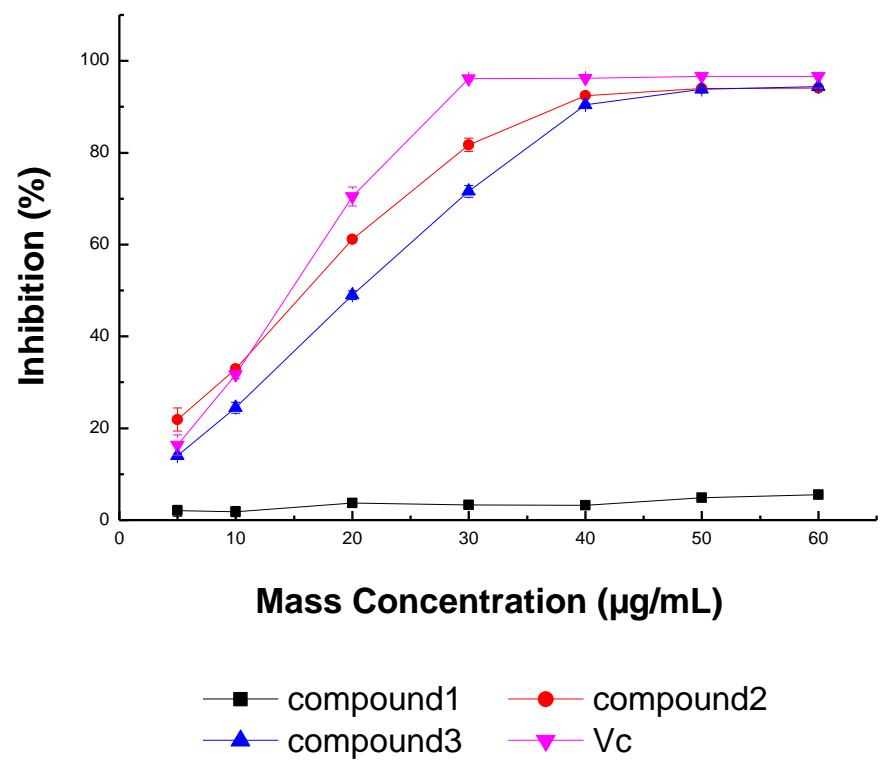

Fig. 17. Relationship between 3 purified flavonoids and DPPH scavenging rate

\section{Antidiabetic Activities}

Figure 18 (A) shows that the IC50 values of compound 2 and compound 3 were $0.752 \mathrm{mg} \cdot \mathrm{mL}^{-1}$ and $0.655 \mathrm{mg} \cdot \mathrm{mL}^{-1}$, while compound 1 had no semi-inhibition rate. The $\mathrm{IC}_{50}$ value of the positive control acarbose was $0.456 \mathrm{mg} \cdot \mathrm{mL}^{-1}$. Therefore, the order of inhibitory activity of $\alpha$-amylase was as follows: compound 3 (catechin) $>$ compound 2 (epicatechin) > compound 1 ((E) -1-methoxy-2-o -(p-coumaroyl)-myo- inositol). This may be because that the 3-OH in the structure of catechins and epicatechins, and the hydroxyl substitution on its B ring would increase their ability to inhibit the activity of $\alpha$-amylase (Liu et al. 2011).

$\alpha$-Glucosidase inhibitors delay and alleviate the time and progression of a diabetic patient's postprandial blood glucose elevation effectively; thus $\alpha$-glucosidase inhibitors may make great contribution in treating diabetes and the occurrence of complications (Jiang et al. 2017b; Chen et al. 2019).

Figure 18 (B) shows the relationship between the $\alpha$-glucosidase inhibitory activity of acarbose and 3 purified flavonoids. The inhibitory activity of $\alpha$-glucosidase increased gradually with increasing concentration of the samples. However, the $\alpha$-glucosidase inhibition capacity of compound 1 was very weak, with no significant change when the concentration increased from 300 to $1800 \mathrm{~g} \cdot \mathrm{mL}^{-1}$. The order of $\alpha$-glucosidase inhibition of the three compounds was compound 3 (catechin) $>$ compound 2 (epicatechin) $>$ compound 
1 ((E)-1-methoxy-2-o-(p-coumaroyl)-myo-inositol). $\alpha$-Glucosidase inhibitory activities means that the glucose absorption progress and postprandial hyperglycemia have been suppressed, which affected the serum glucose concentration, which is related to type II diabetes (Kellogg et al. 2014). Compared with the ability of $\alpha$-amylase inhibitory activity of three pure compounds, catechin and epicatechin were good inhibitors for type II diabetes.

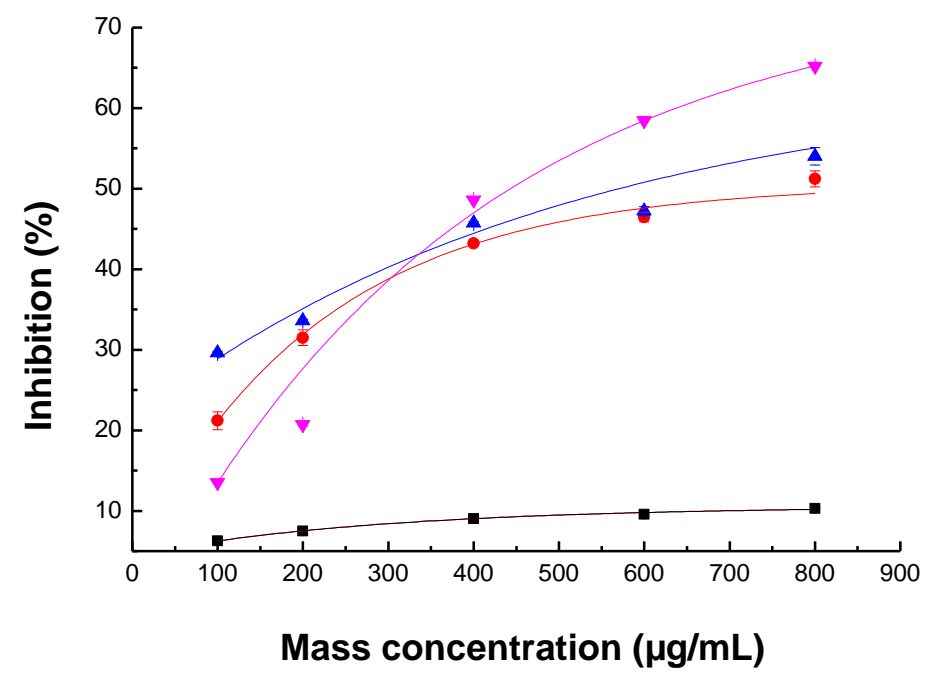

- Compound1 - Compound2

$\Delta$ Compound3 $\nabla$ Acarbose

A

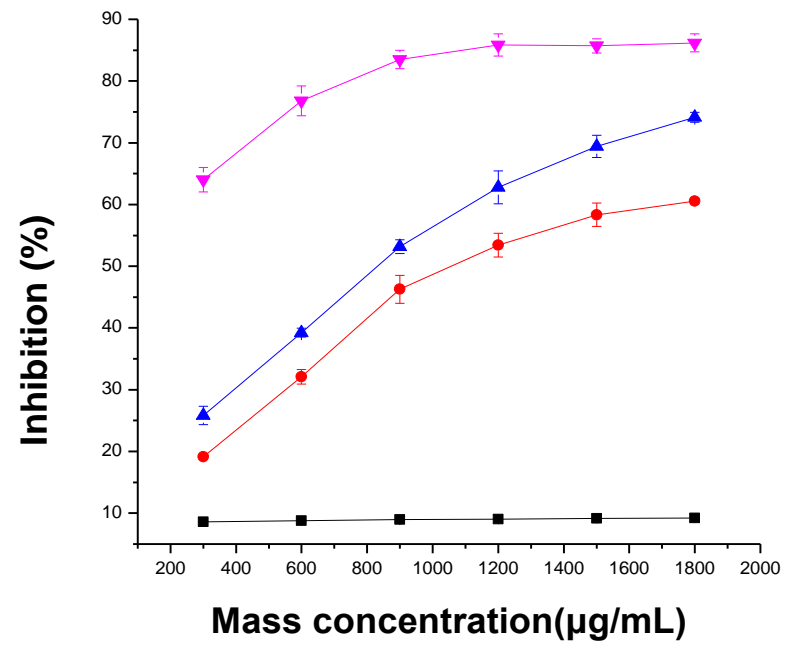

$\begin{array}{ll}\rightarrow \text { Compound1 } & \longrightarrow \text { Compound2 } \\ - \text { Compound3 } & \rightarrow \text { Acarbose }\end{array}$

B

Fig. 18. Results of antidiabetic activity of 3 purified flavonoids against $\alpha$-amylase $(A)$ and $\alpha$ glucosidase (B) 


\section{Antitumor Activity}

The antitumor activity against MCF-7, Hela, and Hepg-2 cells were evaluated using in vitro essays (Fig. 19 and Table 4).
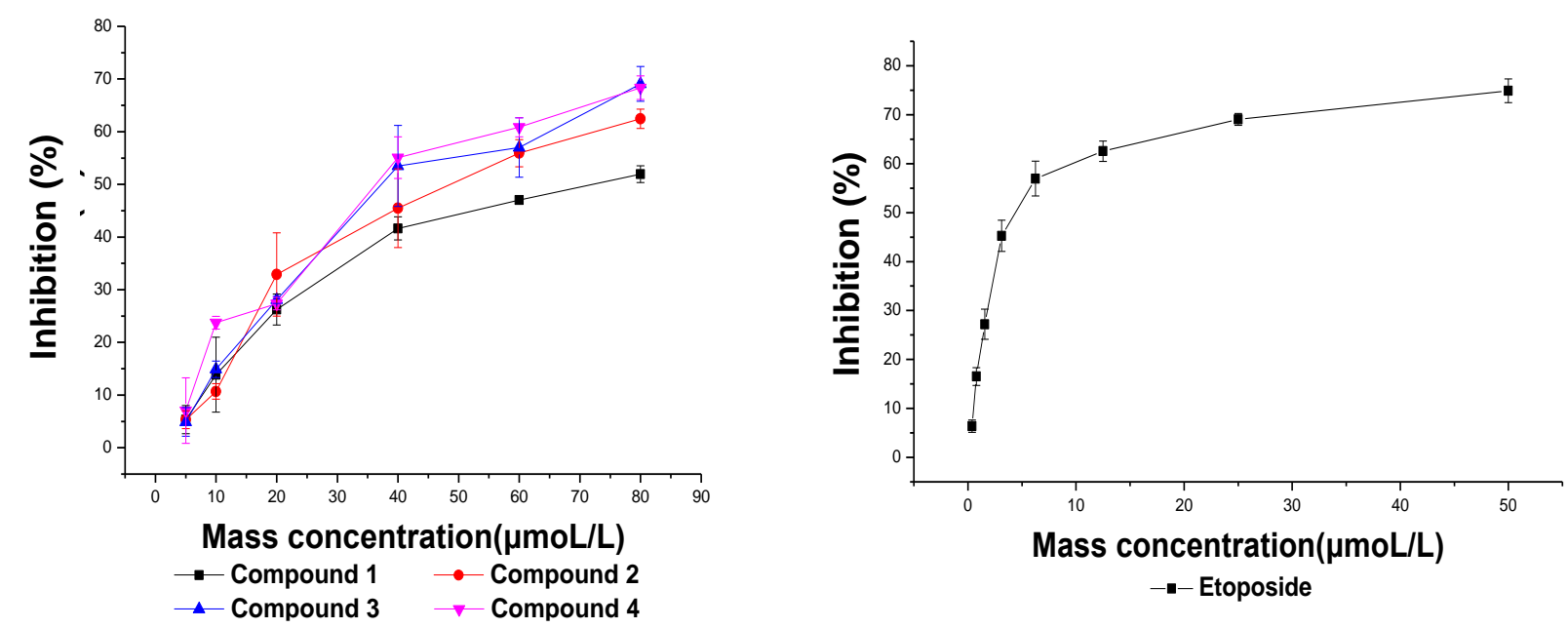

A
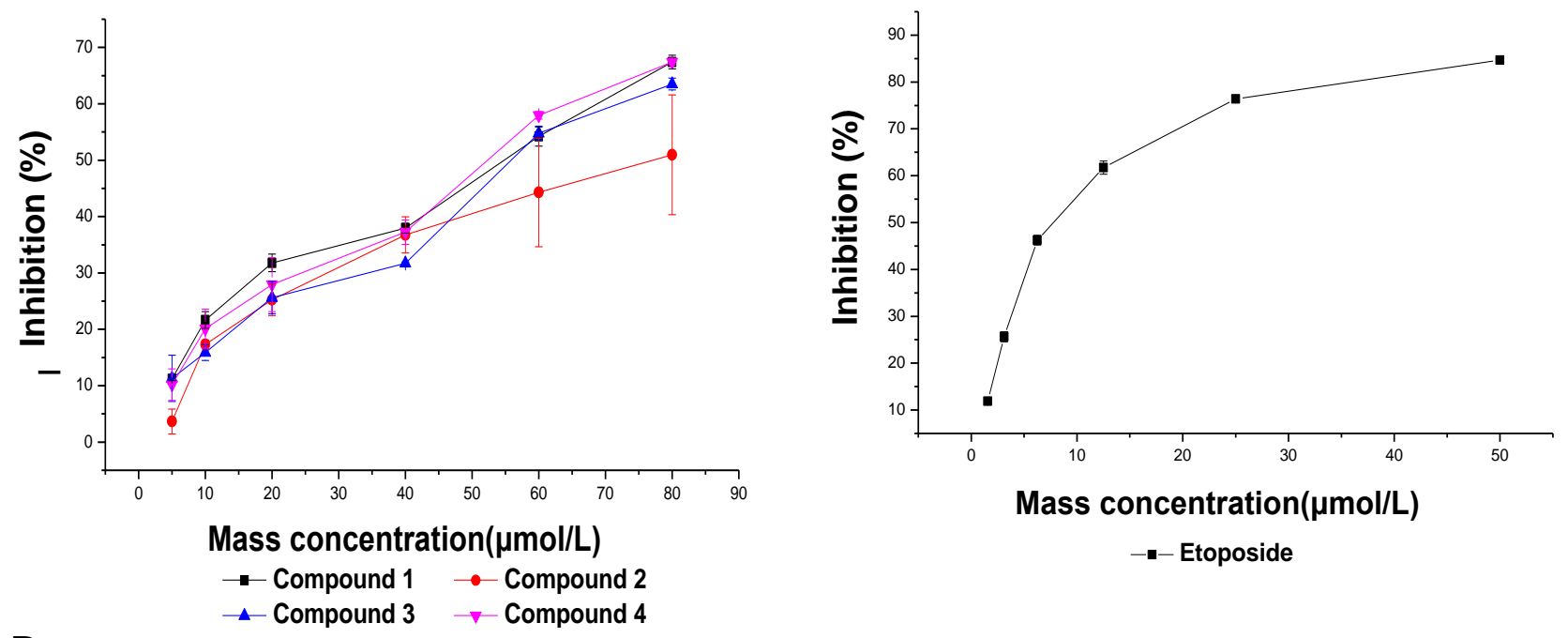

B
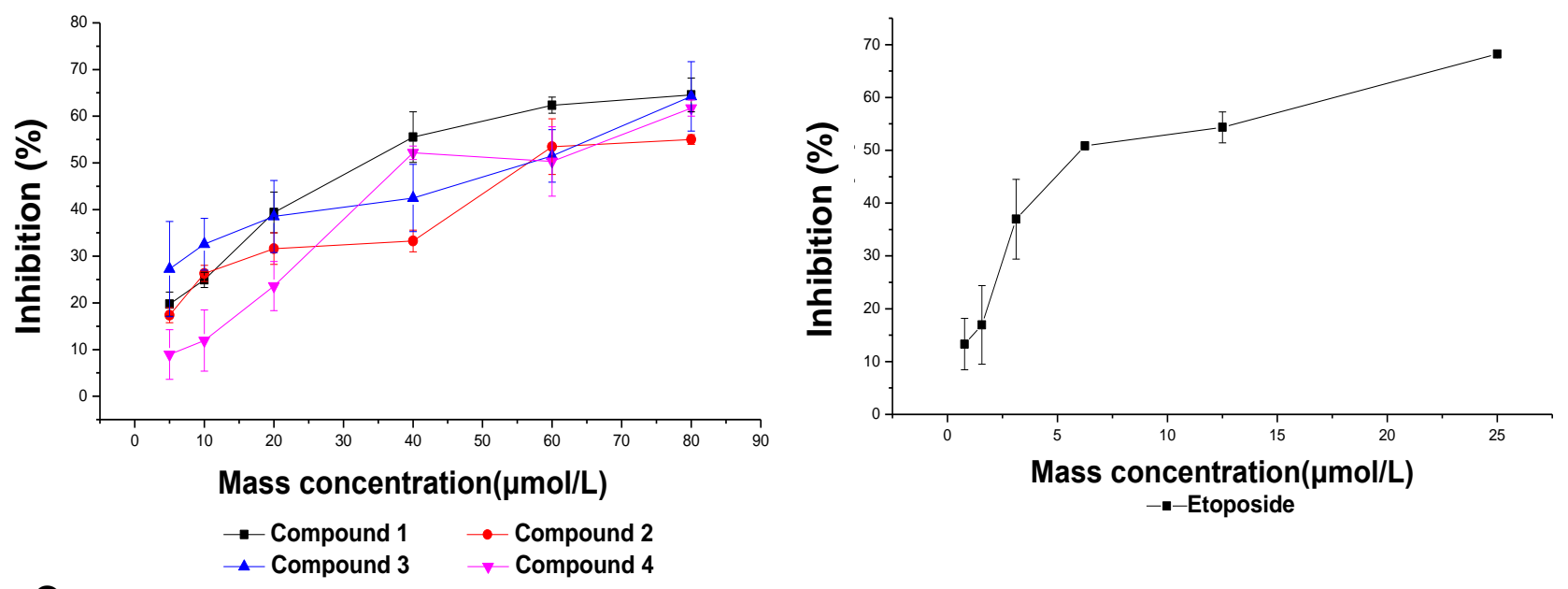

C

Fig. 19. Antitumor activities of 4 purified flavonoids against MCF7 (A), Hela (B), and HepG2 (C) 
Compound 4 had the greater capacity inhibiting MCF7 and Hela activity with $\mathrm{IC}_{50}$ values of $36.4 \mu \mathrm{mol} \cdot \mathrm{L}^{-1}$ and $52.5 \mu \mathrm{mol} \cdot \mathrm{L}^{-1}$, respectively. Compound 1 demonstrated a good inhibitory capacity against $\mathrm{HepG} 2$ with an $\mathrm{IC}_{50}$ value of $33.8 \mu \mathrm{mol} \cdot \mathrm{L}^{-1}$, while the $\mathrm{IC}_{50}$ value of etoposide, an antitumor drug, was $5.9 \mu \mathrm{mol} \cdot \mathrm{L}^{-1}$. Therefore, it was concluded that the flavonoids from TCBL can serve as potential candidates for natural bioactive antitumor drugs.

Table 4. IC $\mathrm{C}_{50}$ Value of 4 Purified Flavonoids Against MCF7, Hela and HepG2

\begin{tabular}{|c|c|c|c|}
\hline \multirow{2}{*}{ 4 Purified Flavonoids } & \multicolumn{3}{|c|}{$\mathrm{IC}_{50} \mu \mathrm{mol} \cdot \mathrm{L}^{-1}$} \\
\cline { 2 - 4 } & $\mathrm{MCF} 7$ & $\mathrm{Hela}$ & $\mathrm{HepG} 2$ \\
\hline Compound 1 & $75.7 \pm 0.05$ & $54.7 \pm 0.04$ & $33.8 \pm 0.05$ \\
\hline Compound 2 & $49.2 \pm 0.02$ & $77.8 \pm 0.07$ & $56.7 \pm 0.02$ \\
\hline Compound 3 & $37.3 \pm 0.02$ & $56.1 \pm 0.02$ & $57.1 \pm 0.02$ \\
\hline Compound 4 & $36.4 \pm 0.05$ & $52.5 \pm 0.03$ & $38.3 \pm 0.01$ \\
\hline Etoposide & $4.5 \pm 0.03$ & $7.8 \pm 0.01$ & $5.9 \pm 0.04$ \\
\hline
\end{tabular}

\section{CONCLUSIONS}

1. The highest flavonoid yields from Taxus cuspidata branches and leaves (TCBL) were obtained by the enzymatic hydrolysis and ultrasound-assisted extraction (EHUE) method. The optimal conditions were: an enzymatic hydrolysis temperature of $48{ }^{\circ} \mathrm{C}$, an enzymolysis time of $39 \mathrm{~min}$, and an enzyme concentration of $0.10 \mathrm{mg} \cdot \mathrm{mL}^{-1}$. The flavonoids yield obtained under the optimized conditions was $5.23 \% \pm 0.18 \%$.

2. Compared to the authors' previous study of TCBL flavonoids using ultrasound-assisted extraction methods alone (yield up to 4.48\%), the current study for enzymatic hydrolysis and ultrasound-assisted extraction (EHUE) method is novel and more beneficial ( $6 \%$ higher yield). The method is a combination of enzyme treatment and ultrasound-assisted extraction methods. The raw materials of TCBL after being treated with pectinase enzyme has a higher extraction rate of total flavonoids than the ultrasound-assisted extraction alone and traditional extraction methods. Enzymatic hydrolysis extraction can loosen and break up the plant cell wall, thus reducing the mass transfer resistance, enhancing the permeability of plant cell wall, and improving the extraction rate of effective ingredients. The extraction conditions are mild, which greatly improve the extraction efficiency. Therefore, this method can be widely used in the extraction of flavonoids of TCBL.

3. Four compounds (E)-1-methoxy-2-O-(p-coumaroyl)-myo-inositol, catechin acid, epicatechin, and quercetin-3-O-glucoside were purified from TCBL ethyl acetate extract. These were mainly composed of flavonoids. Epicatechin showed the greatest antioxidant capacity ( $\mathrm{IC}_{50}$ value: $16.88 \mu \mathrm{mol} \cdot \mathrm{L}^{-1}$ ), while catechin also revealed a potent antioxidant activity (IC50 value: $20.20 \mu \mathrm{mol} \cdot \mathrm{L}^{-1}$ ). They both have strong inhibitory activities on $\alpha$-amylase and $\alpha$-glucosidase as well, which demonstrated the TCBL extract could be potential inhibitors for type II diabetes. Moreover, the extracts exerted clear anticancer activities against MCF-7, Hela, and HepG2 cells. The strongest anticancer activities against MCF7 and Hela were exerted by compound 4 with $\mathrm{IC}_{50}$ values of $36.4 \mu \mathrm{mol} \cdot \mathrm{L}^{-1}$ and $52.5 \mu \mathrm{mol} \cdot \mathrm{L}^{-1}$, respectively and compound 4 possessed a good inhibitory capacity against HepG2 cells with an $\mathrm{IC}_{50}$ value of $33.8 \mu \mathrm{mol} \cdot \mathrm{L}^{-1}$. 
TCBL also contained various health-benefited polysaccharides. Therefore, flavonoids and other effective components in TCBL presented good bioactivities and make it a source of potential inhibitors of type II diabetes and human cervical cancer activity, and may contribute to the future biomedical industry. Further research may be performed on the bioavailability, bioaccessibility, and in vivo bioactivities to confirm the benefit.

\section{ACKNOWLEDGEMENTS}

The authors are grateful to be supported in part by the following: The National Key Research and Development Program of China (2017YFD0601306), Priority Academic Program Development of Jiangsu Higher Education Institutions (PAPD), and Top-notch Academic Program Project of Jiangsu High Education Institutions (TAPP).

\section{REFERENCES}

Bajpai, V. K., Sharma, A., Moon, B., and Baek, K.-H. (2014). "Chemical composition analysis and antibacterial mode of action of Taxus cuspidata leaf essential oil against foodborne pathogens," Journal of Food Safety 34(1), 9-20. DOI: 10.1111/jfs.12089

Cai, M., Luo, Y., Chen, J., Liang, H., and Sun, P. (2014). "Optimization and comparison of ultrasound-assisted extraction and microwave-assisted extraction of shikimic acid from Chinese star anise," Separation and Purification Technology 133 (2014) 375379. DOI: 10. 1016/j.seppur.2014.06.064

Chen, X., Xiong, J., He, Q., and Wang, F. (2019). "Characterization and potential antidiabetic activity of proanthocyanidins from the barks of Acacia mangium and Larix gmelinii," Journal of Chemistry 2019, Article ID 4793047. DOI: $10.1155 / 2019 / 4793047$

Cren-Olivé, C., Wieruszeski, J. M., Maes, E., and Rolando, C. (2002). "Catechin and epicatechin deprotonation followed by ${ }^{13}$ C NMR," Tetrahedron Letters 43(25), 4545 4549. DOI: 10.1016/S0040-4039(02)00745-1.

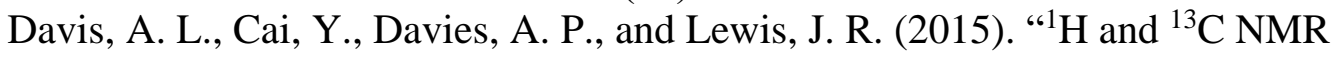
assignments of some green tea polyphenols," Magnetic Resonance in Chemistry 34(11), 887-890. DOI: 10.1002/(SICI)1097-458X(199611)34:11<887::AIDOMR995>3.0.CO;2-U

Durak, Z. E., Buber, S., Devrim, E., Kocaolu, H., and Durak, I. (2014). “Aqueous extract from Taxus baccata inhibits adenosine deaminase activity significantly in cancerous and noncancerous human gastric and colon tissues," Pharmacognosy Magazine 10 (S2), S214-S216.

Dutta, S., Mariappan, G., Sarkar, D., and Sarkar, P. (2010). “Assessment of antiinflammatory activity of Taxus baccata Linn. bark extract," Ancient Sci Life 29 (3), 19-21.

Elansary, H.O., Szopa, A., Kubica, P., A. Al-Mana, F., Mahmoud, E. A., Zin El-Abedin, T.K.A., Mattar, M. A., and Ekiert, H. (2019). "Phenolic compounds of Catalpa speciosa, Taxus cuspidata, and Magnolia acuminata have antioxidant and anticancer activity," Molecules 24, 412. DOI: 10.3390/molecules24030412

Grobosch, T., Schwarze, B., Felgenhauer, N., Riesselmann, B., Roscher, S., and 
Binscheck, T. (2013). "Eight cases of fatal and non-fatal poisoning with Taxus baccata," Forensic Science International 227 (1-3), 118-126. DOI: 10.1016/j.forsciint.2012.11.014

Han, Z. P., Cui, H. Y., and Zhang, Z. Z. (2015). "Response surface method was used to optimize the extraction process of total flavonoids from sweet almond skin," Anhui Agricultural Sciences 43(28), 278-281,284.

Hao, D. C., Ge, G. B., Xiao, P. G., Zhang, Y., and Yang, L. (2011). "The first insight into the tissue specific taxus transcriptome via Illumina second generation sequencing," PLoS One 6, e21220. DOI: 10.1371/journal.pone.0021220

Hou, X. M., Li, L. X., Feng, Z. Z., and Yan, G. Q. (2013). "Response surface method was used to optimize the extraction process and antioxidant activity of total flavonoids from mint leaves," Food Science 34(6), 124-128.

Hye, M. A., Taher, M. A., Ali, M. Y., and Ali, M. U. (2009). "Isolation of (+)catechin from Acacia catechu (cutch tree) by a convenient method," Journal of Scientific Research 2009, 1(2). DOI: 10.3329/jsr.v1i2.1635

Jiang, P., Chen, H. F., Huang, H. B., Bao X. Y., and Xu, L. (2017a). "Ultrasonic-assisted extraction of total flavonoids from branches and leaves of Taxus cuspidata Sieb. et Zucc. and its antioxidant activity," Chemistry and Industry of Forest Products 37(6), 125-132.

Jiang, P., Xiong, J., Wang, F., Grace, M. H., and Xu, R. (2017b). " $\alpha$-Amylase and $\alpha$ glucosidase inhibitory activities of phenolic extracts from Eucalyptus grandis $\mathrm{x} E$. urophylla bark," Journal of Chemistry 9, Article ID 8516964. DOI: $10.1155 / 2017 / 8516964$

Kellogg, J., Grace, M. H., and Lila, M. A. (2014). "Phlorotannins from Alaskan seaweed inhibit carbolytic enzyme activity," Marine Drugs 12(10), 5277-5294.

Kobayashi, J., and Shigemori, H. (2002). "Bioactive taxoids from the Japanese yew Taxus cuspidata," Medicinal Research Reviews, 22, 305. DOI: 10.1002/med.10005

Kobayashi, J., and Shigemori, H. (1999). "Bioactive taxoids from japanese yew Taxus cuspidata and taxol biosynthesis," Heterocycles 47, 1111-1133. DOI: 10.3987/REV97-SR(N)7

Li, J. F., Cai, D. K., Bi, H. C., Jin, J., and Huang, M. (2013). "Effects of flavonoids derived from Taxus yunnanensis on p-glycoprotein and cytochrome P450 3A4," Asian Journal of Pharmaceutical Sciences 8(3), 168-173. DOI: 10.1016/j.ajps.2013.07.022.

Li, Y., Guo, R. X., Wu, Y. B., Sauriol, F., Shi, Q. W., Gu, Y. C., and Bin, C. (2013). “A new taxane from the needles of Taxus cuspidata," Chemistry of Natural Compounds 49, 277-280. DOI: 10.1007/s10600-013-0581-5

Liu, J. C., Jiao, Z. G., and Wang, S. X. (2011). "The inhibitory effect of polyphenols extract from apple on $\alpha$-amylase and $\alpha$-glucosidase," Journal of Fruit Science 28(4), 553-557.

Patel, P., Patel, K., and Gandhi, T. (2011). "Evaluation of effect of Taxus baccata leaves extract on bronchoconstriction and bronchial hyperreactivity in experimental animals," Journal of Young Pharmacists 3 (1), 41-47. DOI: 10.4103/09751483.76418

Rosa, A., Tuberoso, C. I. G., Atzeri, A., Melis, M. P., Bifulco, E., and Dessi, M. A. (2011). "Antioxidant profile of strawberry tree honey and its marker homogentisic acidin several models of oxidative stress," Food Chemistry 129(3), 1045-1053. DOI: 10.1016/j.foodchem.2011.05.072 
Shigemori, H., and Kobayashi, J. (2004). "Biological activity and chemistry of taxoids from the Japanese yew, Taxus cuspidata," Journal of Natural Products 67(2), 245256.

Spjut, R. W. (2007). “Taxonomy and nomenclature of Taxus (Taxaceae)," Journal of the Botanical Research Institute of Texas 1, 203-289.

Tang, B., Zhang, F.S., Li, X., Chen, J. W., and Xiao, Y. (2013). "Supercritical CO2 fluid extraction and component analysis of leaves oil from Taxus chinensis var. mairei," Zhong Yao Cai 36 (12), 2023-2027.

Tezuka, Y., Morikawa, K., Li, F., Auw, L., Awale, S., Nobukawa, T., and Kadota, S. (2011). "Cytochrome P450 3A4 inhibitory constituents of the wood of Taxus yunnanensis," Journal of Natural Products. 74 (1), 102-105. DOI: 10.1021/np100665j

Van Rozendaal, E. L., Lelyveld, G. P., and Van Beek, T. A. (2000). "Screening of the needles of different yew species and cultivars for paclitaxel and related taxoids," Phytochemistry 53, 383-389. DOI: 10.1016/S0031-9422(99)00094-1

Wang, H., and Liu, J. J. (2004). "Enzymatic extraction of flavonoids from ginkgo biloba," Forest Products Chemical Communication 38(1), 15-16.

Wu, D., Li, Y. N., Wu, L.J. and Gao, H. Y. (2010). "Isolation and identification of chemical constituents of Taxus cuspidata," Chinese Journal of Pharmacy 2010, 28(11), 1398-1401. DOI: 10.16438/j.0513-4870.2010.11.005

Wu, M., and Wu, Y. (2009). "Structural characterisation of a water-soluble polysaccharide with high branches from the leaves of Taxus chinensis var. mairei," Food Chem. 113, 1020-1024. DOI: 10.1016/j.foodchem.2008.08.055

Yan, C. Y., Yin, Y., Zhang, D. W., Yang, W., and Yu, R. M. (2013). "Structural characterization and in vitro antitumor activity of a novel polysaccharide from Taxus yunnanensis," Carbohydrate Polymers 96(2), 389-395. DOI: 10.1016/j.carbpol.2013.04. 012

Zou, J. G., Liu, F., Liu, Y. Y., Peng, H. L., Li, B. H., Fu, H. Q., and Xiao, J. M. (2012). "Optimization of microwave-assisted extraction of total flavonoids from Fructus aurantii Immaturus by response surface methodology," Food Science 33(2), 24-28.

Zhang, D., Meng, H., and Yang, H. S. (2012). "Antidiabetic activity of Taxus cuspidata polysaccharides in streptozotocin induced diabetic mice," International Journal of Biological Macromolecules 50, 720-724. DOI: 10.1016/j.ijbiomac.2011.12.020

Zheng, Z. Q., Fu, Y. Y., Li, B. H., Zhang, M. L., and Yang, X. L. (2014). "PSY-1, a Taxus chinensis var. mairei extract, inhibits cancer cell metastasis by interfering with MMPs," Natural Product Communications 9, 241-245. DOI: 10.1021/np5001208

Article submitted: August 5, 2020; Peer review completed: October 31, 2020; Revised version received and accepted: February 9, 2021; Published: February 19, 2021.

DOI: 10.15376/biores.16.2.2655-2682 


\section{APPENDIX}

\section{Supplementary Figures}

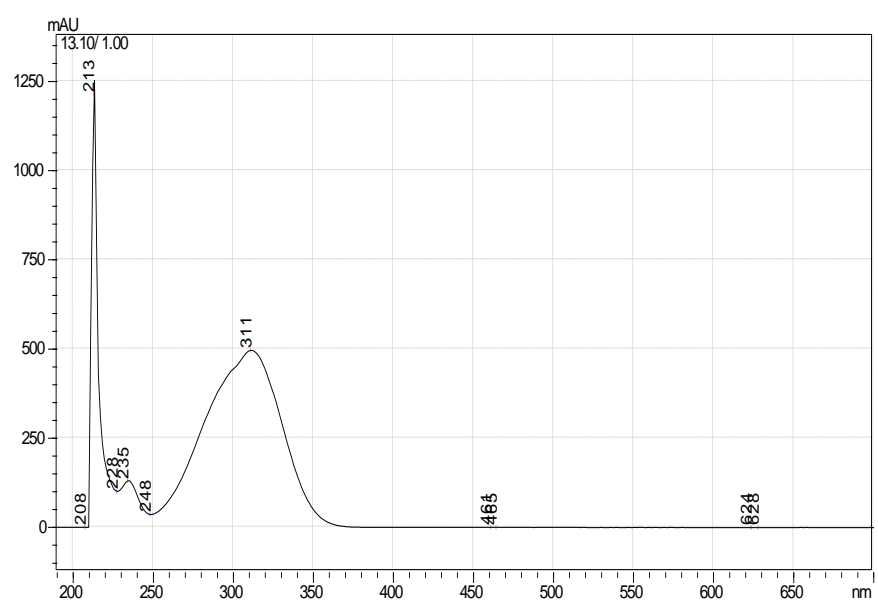

Fig. S1. UV absorption spectrum of Compound1

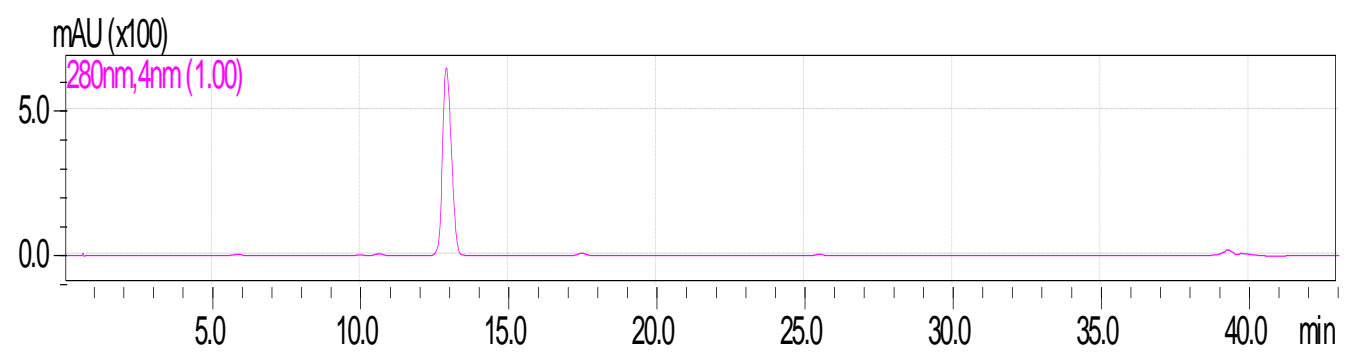

Fig. S2. High performance liquid chromatogram of Compound1

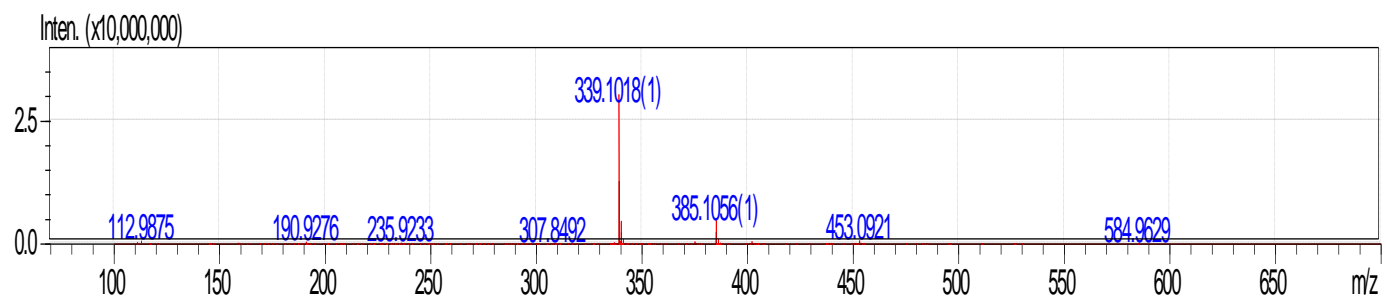

Fig. S3. ESI-MS spectrum of compound1

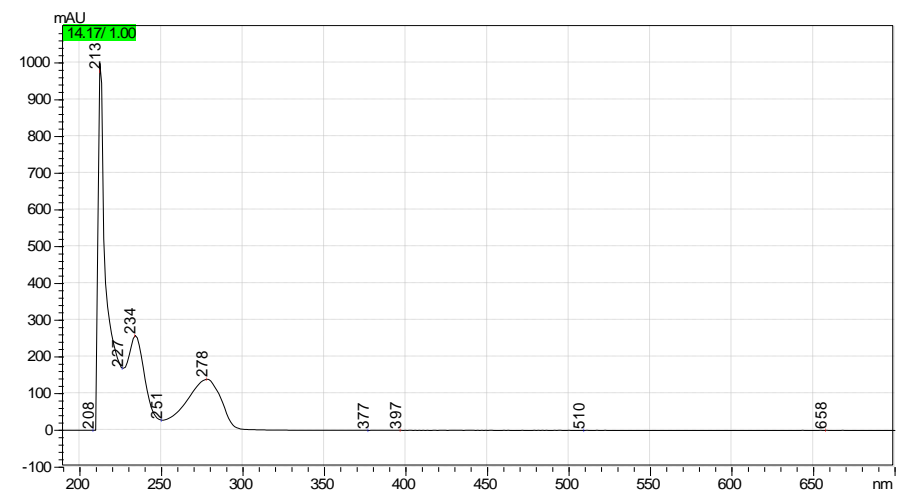

Fig. S4. UV absorption spectrum of compound 2 


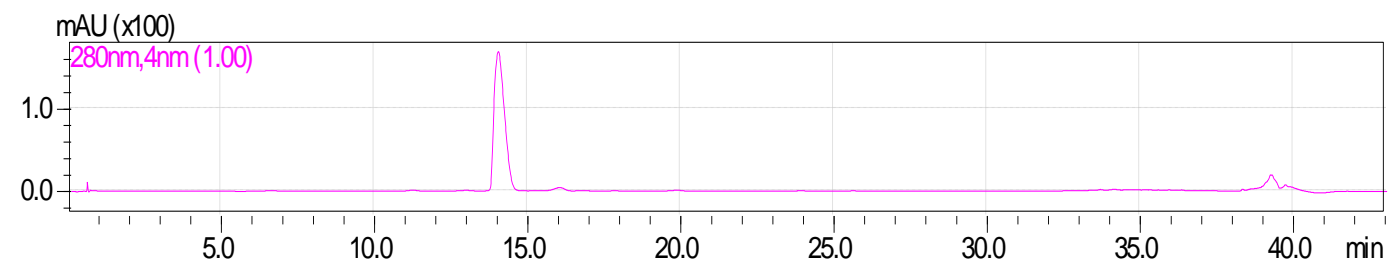

Fig. S5. High performance liquid chromatogram of compound 2

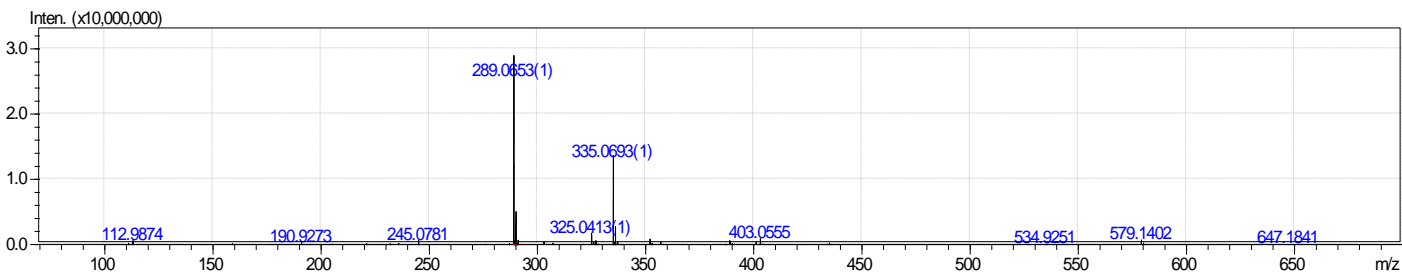

Fig. S6. ESI-MS spectrum of compound 2

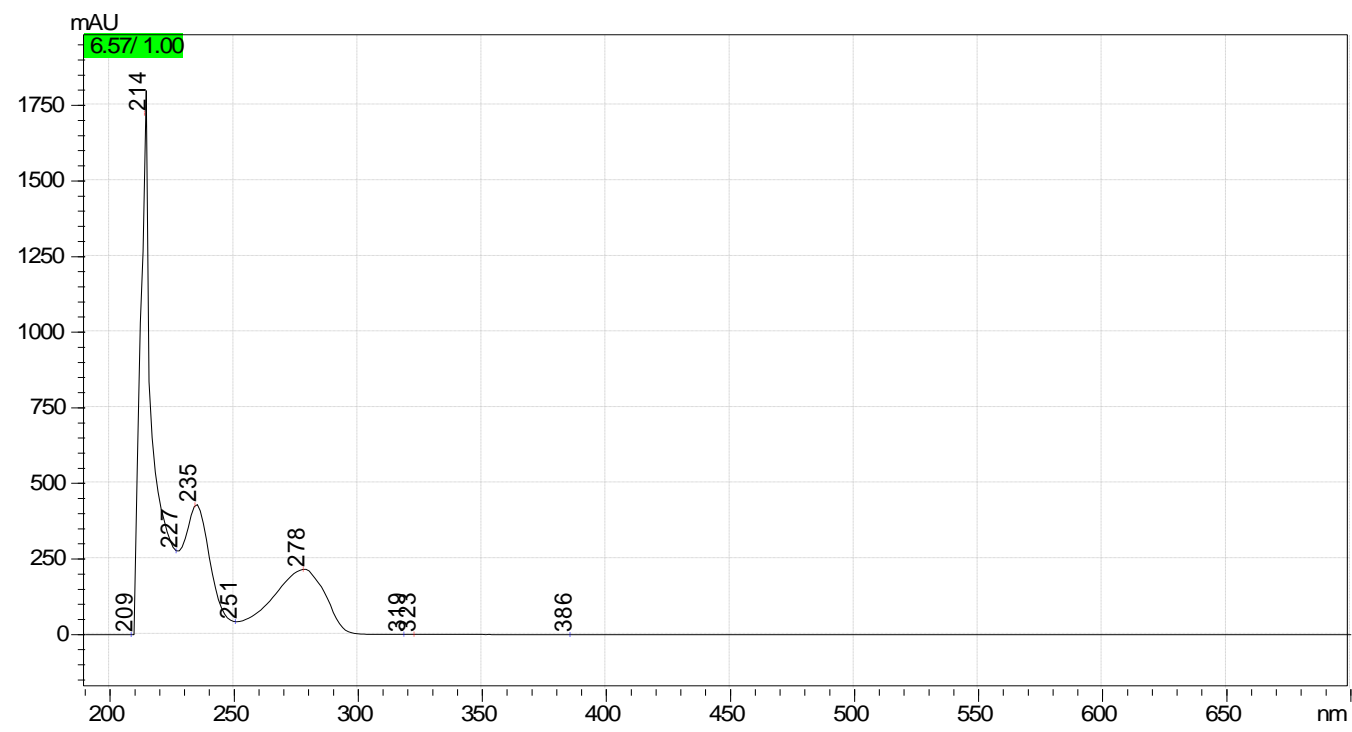

Fig. S7. UV absorption spectrum of compound 3

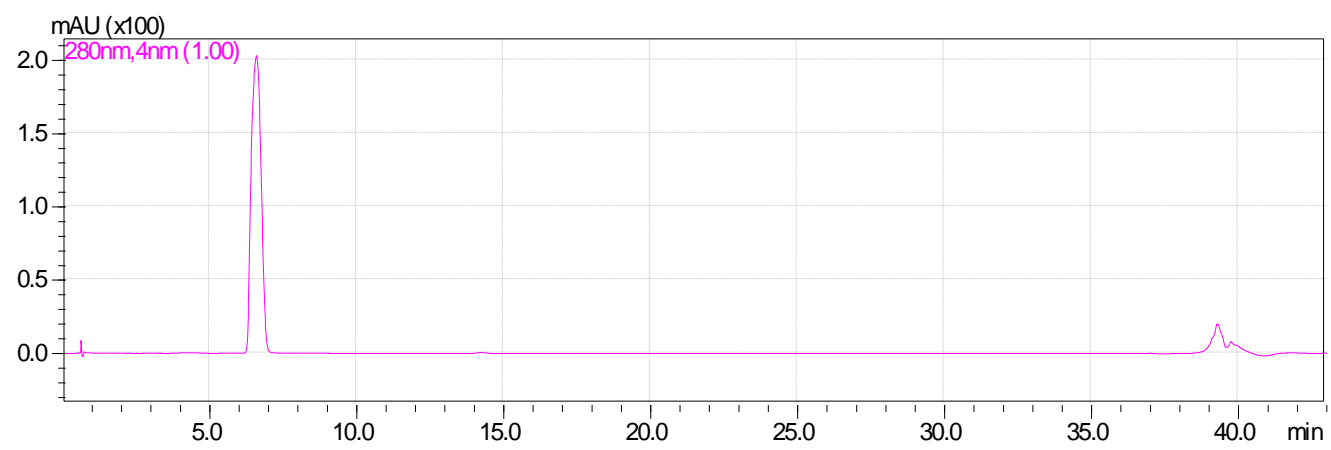

Fig. S8. High performance liquid chromatogram of compound 3 


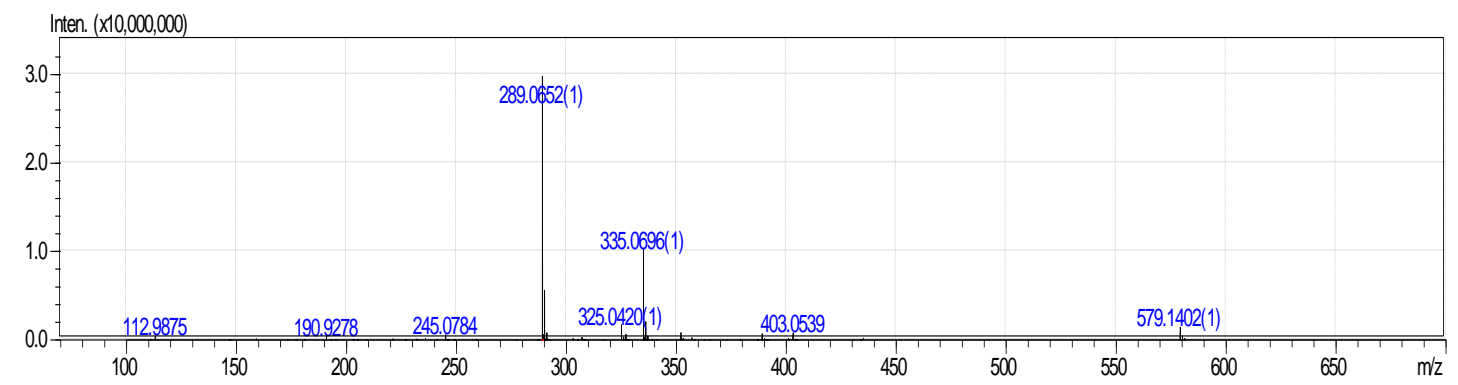

Fig. S9. ESI-MS spectrum of compound 3

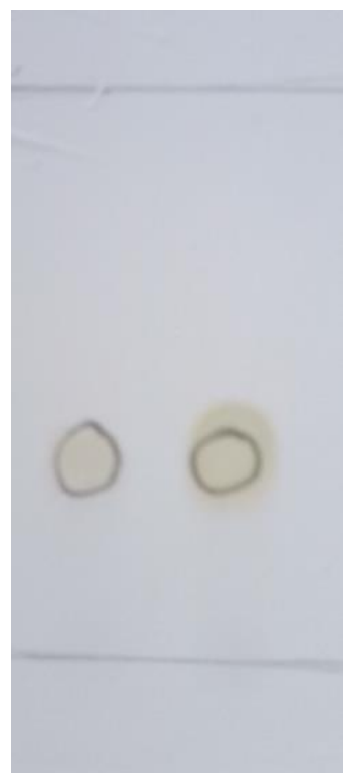

Fig. S10. The thin-layer chromatography of compound 3

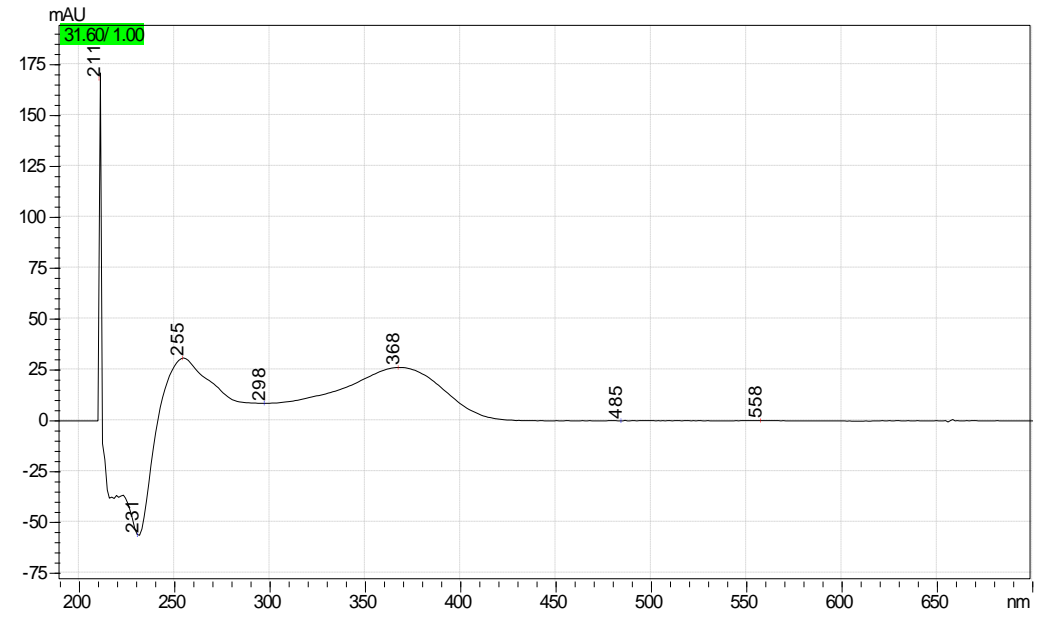

Fig. S11. UV absorption spectrum of compound 4 


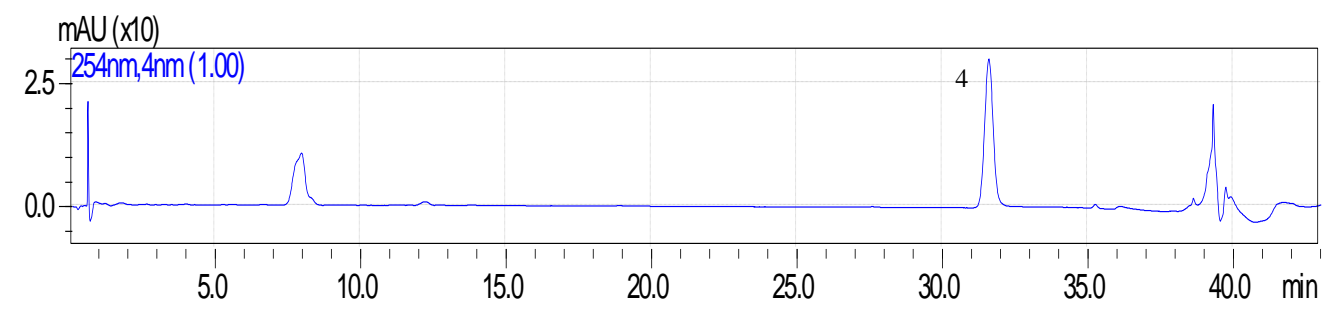

Fig. S12. High performance liquid chromatogram of compound 4

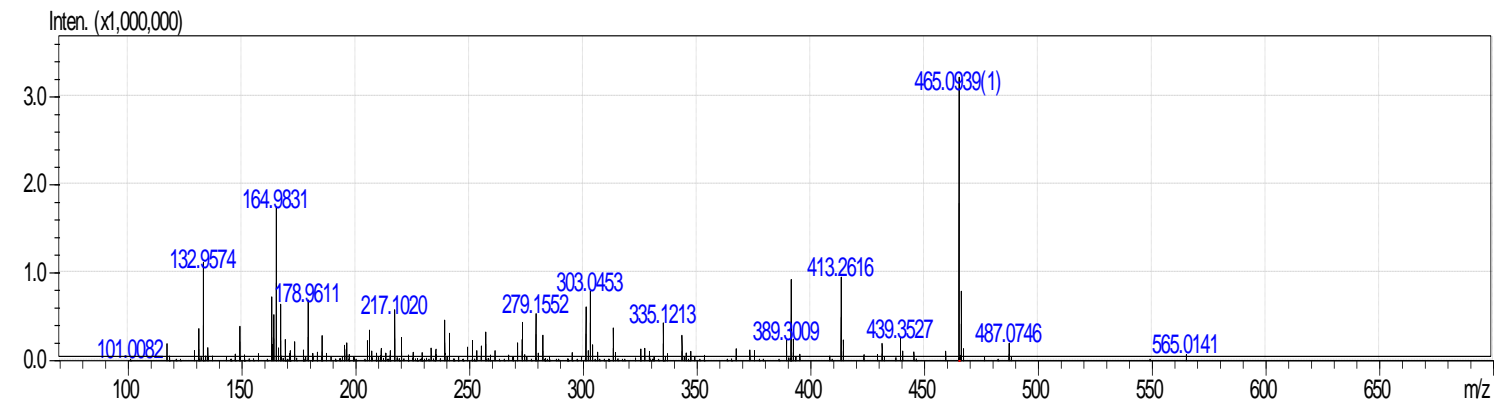

Fig. S13. ESI-MS ${ }^{+}$spectrum of compound 4 